San Jose State University

SJSU ScholarWorks

Master's Theses

Master's Theses and Graduate Research

Fall 2019

\title{
Association of Food Pharmacy Participation With Type II Diabetes Risk Factors
}

Breanne Vinogradoff

San Jose State University

Follow this and additional works at: https://scholarworks.sjsu.edu/etd_theses

\section{Recommended Citation}

Vinogradoff, Breanne, "Association of Food Pharmacy Participation With Type II Diabetes Risk Factors" (2019). Master's Theses. 5086.

DOI: https://doi.org/10.31979/etd.hdt9-pzvj

https://scholarworks.sjsu.edu/etd_theses/5086

This Thesis is brought to you for free and open access by the Master's Theses and Graduate Research at SJSU ScholarWorks. It has been accepted for inclusion in Master's Theses by an authorized administrator of SJSU ScholarWorks. For more information, please contact scholarworks@sjsu.edu. 


\title{
ASSOCIATION OF FOOD PHARMACY PARTICIPATION WITH TYPE II DIABETES RISK FACTORS
}

\author{
A Thesis \\ Presented to \\ The Faculty of the Department of Nutrition, Food Science, and Packaging \\ San José State University \\ In Partial Fulfillment \\ of the Requirements for the Degree \\ Master of Science \\ by \\ Breanne R. Vinogradoff
}

December 2019 
(C) 2019

Breanne R. Vinogradoff

ALL RIGHTS RESERVED 
The Designated Thesis Committee Approves the Thesis Titled

\title{
ASSOCIATION OF FOOD PHARMACY PARTICIPATION WITH TYPE II DIABETES RISK FACTORS
}

\author{
by \\ Breanne Vinogradoff \\ APPROVED FOR THE DEPARTMENT OF NUTRITION
}

SAN JOSÉ STATE UNIVERSITY

December 2019

John Gieng, PhD

Giselle Pignotti, PhD, RD

Marcelle Dougan ScD, MPH, MEng
Department of Nutrition

Department of Nutrition

Department of Health Science and Recreation 


\title{
ABSTRACT
}

\section{ASSOCIATION OF FOOD PHARMACY PARTICIPATION WITH TYPE II DIABETES RISK FACTORS}

\author{
by Breanne R. Vinogradoff
}

Food insecurity is defined as a lack of access to enough food for a healthy lifestyle and has been found to lead to higher prevalence of type 2 diabetes (T2DM). In recognition of this relationship, many safety-net clinics and food banks have introduced "food pharmacies." The term "food pharmacy" may be used to describe a treatment model that focuses on provision of disease-specific, medically appropriate food. This observational study examined data from a food pharmacy in the San Francisco Bay Area to determine if program participation improved clinical measures of T2DM status or risk, namely glycated hemoglobin (HbA1c), fasting blood glucose (FBG), and body mass index (BMI). Analysis found a significant inverse correlation between program participation and BMI at 24 months after enrollment. At 24 months, individuals who participated above the median rate had significantly lower BMIs than those below the median rate. Conversely, there was no correlation found between participation and $\mathrm{HbAlc}$, despite significant decreases in mean $\mathrm{HbA1c}$ from baseline at 18 months in subgroup analysis. In conclusion, participating in existing San Francisco Bay Area food pharmacies does not appear to improve T2DM clinical markers, aside from BMI. A modification of the food pharmacy treatment model should be considered if public programs want to effectively target T2DM in food insecure individuals. 


\section{ACKNOWLEDGMENTS}

This thesis was made possible through the advice and assistance of San Jose State University advisors and food pharmacy staff. Thank you to Dr. John Gieng for serving as primary advisor and providing valuable guidance throughout this process. Thank you to Dr. Giselle Pignotti and Dr. Marcelle Dougan for offering thoughtful feedback and suggestions that helped to provide direction though the planning and editing phases. An additional thanks is owed to Dr. Jason Wong of Samaritan House community clinics, for facilitating this thesis by providing the datasets used for analysis. Accordingly, this thesis wouldn't have been possible without the support of Samaritan House executives, who approved of this project. Lastly, I owe innumerable thanks to my husband and family, who have consistently supported me throughout my schooling and have provided incredible encouragement. 


\section{TABLE OF CONTENTS}

List of Tables

vii

List of Figures

viii

List of Abbreviations

ix

CHAPTER 1. Literature Review................................................................. 1

Introduction ................................................................................ 1

Food Insecurity - An Overview........................................................... 2

Food Insecurity and T2DM................................................................ 5

Measurable Risk Factors and Indicators ............................................... 7

Food Insecurity and BMI ............................................................... 8

BMI and T2DM.......................................................................... 10

Food Insecurity and Diet Quality .................................................... 12

Diet Quality and T2DM .................................................................. 13

Diet Quality and BMI..................................................................... 15

Safety-Net Resource Programs and T2DM-Related Outcomes................... 16

Conclusion and Areas of Future Research …........................................ 22

CHAPTER 2 - Journal Article ..................................................................... 23

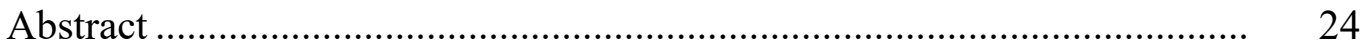

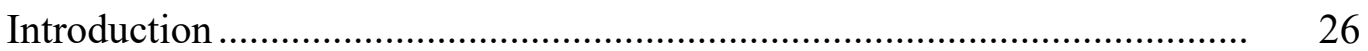

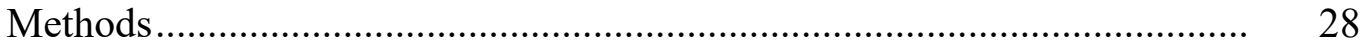

Subjects .................................................................................... 28

Food Pharmacy Program Design ....................................................... 29

Data Collection and Analysis ......................................................... $\quad 30$

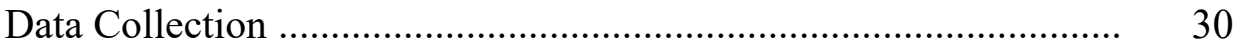

Data Analysis ....................................................................... 31

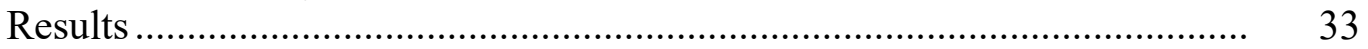

Discussion .................................................................................... 36

Implications for Research and Practice ................................................ 39

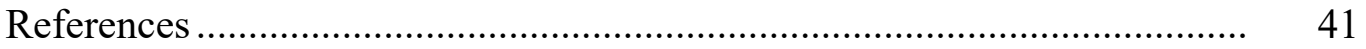

Supplemental Materials............................................................................ 46

CHAPTER 3 - Summary and Conclusions ................................................ 48

Summary ............................................................................... 48

Conclusions …....................................................................................... 49

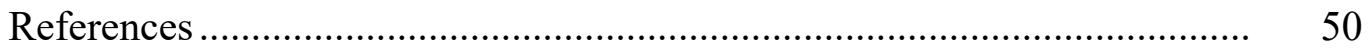

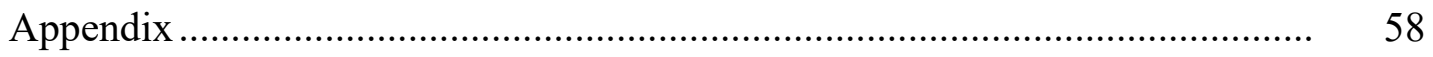

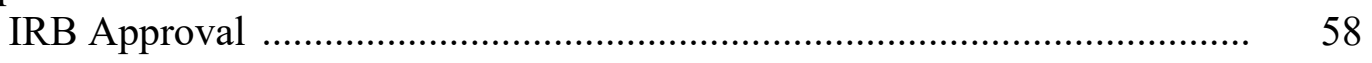




\section{LIST OF TABLES}

Table 1. Summary of Food Pharmacy Studies that Include HbA1c and FBG

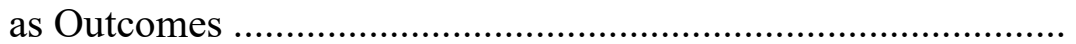

Table 2. Summary of Food Pharmacy Studies which Include Non-Clinical Outcomes..........................................................................

Table 3. Sample Characteristics at Baseline ........................................... 33

Table 4. Sample Characteristics of Proportion of Baseline and Rate of Participation in All Variables at All Time Points .......................

Table 5. Correlation Between Food Pharmacy Participation Rate and Proportion of Baseline ..........................................................

Table 6. Sample Characteristics of Repeated Measures Subsample ........ 36

Table 7. Comparison of Means Between High/Low Participation Groups 46

Table 8. Comparison of Subsample Means Between High/Low Participation Groups 


\section{LIST OF FIGURES}

Figure 1. Hypothesized Mechanism of the Food Pharmacy Model ........... 8

Figure 2. Frequency Distribution of Food Pharmacy Participation Rates at 


\section{LIST OF ABBREVIATIONS}

T2DM - Diabetes mellitus type 2

HbA1c - Glycated hemoglobin

FBG - Fasting blood glucose

BMI - Body mass index

$\propto \Delta$ - Proportion of change 


\section{Chapter 1. Literature Review}

\section{Introduction}

It comes as no surprise that food insecurity, defined as inconsistent access to nutritionally adequate, safe, and acceptable food, is more prevalent among food pantry participants. A recent review of literature from the US, Canada, Australia, and the Netherlands found that half of all pantry clients may be food insecure (Bazerghi, McKay, \& Dunn, 2016). What begins as an immediate problem of hunger often has compounding effects on an individual's wellbeing, resulting in a number of serious health outcomes. Food insecurity has been found to increase the odds of developing of type 2 diabetes (T2DM) by $27 \%$, according to a recent systematic review and meta-analysis of studies, primarily based in the US (Abdurahman, Chaka, Nedjat, Dorosty, \& Majdzadeh, 2019). The national prevalence of T2DM in 2016 and 2017 was $8.5 \%$, placing it among the top 10 most common diseases in the US (Raghupathi \& Raghupathi, 2018; Xu et al., 2018). The global prevalence of T2DM was estimated to be $8.8 \%$ in 2015 (Ogurtsova et al., 2017). New avenues for community-level treatment are emerging among food pantries and community medical clinics; if indeed food insecurity puts individuals at a greater risk of T2DM, local non-profit centers may be situated in an advantageous position to support the affected population by providing medically appropriate food and counseling to affected clients.

This treatment model, herein referred to as a "food pharmacy," has been pioneered by a number of non-profit locations in the US over the last several years. Very few studies have sought to analyze changes in diabetes status among participants. As research 
continues to emerge, it is helpful to consider the supporting theoretical framework that suggests food pharmacies may be able to improve T2DM status. This literature review will seek to describe the overlapping potential mediators of T2DM in the food insecure population. The subsequent research study will seek to determine if a food pharmacy, based on the previously described theoretical framework, produces significant improvements in T2DM markers. Both the review and study will allow for refinement of the food pharmacy model, inform future outcome tracking, and provide evidence-based reasoning for continuing these efforts.

\section{Food Insecurity - An Overview}

The problem of individual inadequacy of food in America was first brought to light in the 1960 s by a number of public health efforts (Radimer \& Radimer, 2002). As awareness grew, a number of national conferences were convened to address this problem and the term "food insecurity" emerged (Radimer \& Radimer, 2002). It was soon apparent that a consistent measurement tool was needed to determine if individuals were food insecure; thus, in 1996, a series of questions addressing food security status were added to the annual US Current Population Survey (Radimer \& Radimer, 2002). These were further refined and became known as the United States Department of Agriculture's (USDA) 18-question Core Food Security Module (Gundersen, 2013). To allow for expedited screenings, there are now ten and six item versions of this questionnaire available ("Usda Ers-Survey Tools," 2019).

In 2018 , the USDA's nationally representative annual survey found that $11 \%$ of households in the United States were food insecure at some point during 2018. 
Encouragingly, rates have been steadily declining since 2011, when the national prevalence of food insecurity was nearly 15\% (Coleman-Jensen, Rabbitt, Gregory, \& Singh, 2019). Rates of food insecurity among households with children was approximately 14\% in 2018 (Coleman-Jensen et al., 2019). In half of these food insecure households, only one or more of the adults experienced some level of food insecurity, while the children maintained a normal or near-normal diet; this left just over 7\% of US households where one or more adults and children experienced a degree of food insecurity (Coleman-Jensen et al., 2019),

A number of risk factors have been found to increase the likelihood that a household experiences food insecurity. Results from a 2014 Gallup World Poll of 123,732 individuals in 134 different countries found that lower education, lack of social support, and low social capital were major determinants of experiencing food insecurity across different country-development rankings; the magnitude of this effect decreased as countries' level of economic development increased (M. D. Smith, Rabbitt, \& ColemanJensen, 2017). In the US, Pruitt et al. (2016) found that food insecurity is more prevalent among those who are less educated, unmarried, have a small poverty-to-income ratio, and live in a household with children. An individual's demographics also appear to predict the likelihood of experiencing food insecurity. Two large, nationally representative surveys in the US have shown Hispanics and non-Hispanic blacks experience significantly higher rates of food insecurity (Hernandez, Reesor, \& Murillo, 2017; Pruitt et al., 2016). 
Gender has been suggested as another potential predictor of food insecurity. In the previously mentioned study of National Health and Nutrition Examination Survey (NHANES) 2005-2010 data, Pruitt et al. (2016) found that females are statistically more likely to be food insecure. There may be more nuance to this relationship, as the 2014 Gallup poll found female gender only significantly increased the probability of experiencing food insecurity in lower-middle income countries, but not in low or highincome countries (M. D. Smith et al., 2017). To further clarify the risk of food insecurity females face internationally, a recently published review conducted a meta-analysis of 42 separate studies from primarily high and medium development-index countries (Jung, Bairros, Pattussi, Pauli, \& Neutzling, 2017). Authors found that, overall, female gender significantly predicted food insecurity; however, in subgroup analysis, this prediction was only significant when female respondents were classified as "heads of household" (Jung et al., 2017). The predictive effect of female gender was statistically insignificant among studies where household composition of respondents was not assessed (Jung et al., 2017). This study primarily included highly developed countries, so applicability of these findings should be limited to similar demographics.

A number of potential reasons for this disparity have been documented, including women's tendency, as primary food provider, to allocate resources to others at their own expense and their increased awareness of household needs (Matheson \& McIntyre, 2014). It appears that female gender does impact the risk of experiencing food insecurity, but caution may be warranted when interpreting results which do not report the composition of households. 
To cope with food insecurity, individuals may turn to a number of community resources available to them, including food pantries and safety-net clinics. Use of food pantries doesn't always preclude food security, but studies of food pantry clients indicate a majority may be classified as some degree of food insecure (Ippolito et al., 2017;

Robaina \& Martin, 2013; Wetherill, Williams, White, \& Seligman, 2019). Food insecure households are also more likely to be classified as living in poverty (Pruitt et al., 2016). Many in poverty rely on the services of safety-net healthcare clinics, which provide free or reduced cost care to those who qualify based on socioeconomic status (Saviano, 2009). Though these clinics qualify clients based on income, not food security status, a majority of clinic patients report a degree of food insecurity. Two such safety-net clinics (one specializing in diabetes care) report that nearly $60-75 \%$ of their clients were classified as food insecure (Marpadga et al., 2019; S. Smith et al., 2017). When seeking to address individuals experiencing food insecurity, it appears that food pantries and safety-net clinics may aptly provide access to this population.

\section{Food Insecurity and T2DM}

Food pharmacies aiming to address T2DM are founded upon the underlying fact that the food insecure population faces much higher rates of this disease than their food secure counterparts. In the US, analysis of large, nationally representative datasets has repeatedly found that food insecurity correlates with T2DM. In an analysis of an older NHANES dataset (1999-2004), Seligman, Laraia, and Kushel (2010) found that food insecurity was significantly correlated with clinically diagnosed T2DM when data were controlled for body mass index (BMI) and demographics. This association remained true 
after analysis of newer NHANES data (1999-2008), wherein authors found that respondents experiencing food insecurity were significantly more likely to have an HbA1c $>9.0 \%$, indicating poorly controlled T2DM, even when data were controlled for BMI (Berkowitz, Baggett, Wexler, Huskey, \& Wee, 2013). Most recently, analysis of 2005-2014 NHANES data indicate that those with prediabetes, undiagnosed T2DM, and diagnosed T2DM were $1.39,1.81$, and 1.58 times more likely to be food insecure, respectively, than those without T2DM (Walker, Grusnick, Garacci, Mendez, \& Egede, 2019). The scale and consistency of these findings indicate the food-insecure population in the US experiences greater rates of T2DM diagnosis.

Research indicates the association between food insecurity and T2DM remains significant among safety-net resource clients, the primary clientele of food pharmacies. In a low-socioeconomic population, Seligman et al. (2012) found that food insecure, safetynet clinic patients were $48 \%$ more likely than food secure patients to have measures of glycated hemoglobin $(\mathrm{HbA} 1 \mathrm{c}) \geq 8.5 \%$, indicating poor glycemic control. These same patients were also found to have more difficulty following the diabetic diet prescribed to them by their doctor, have lower self-efficacy scores, and have higher emotional distress related to diabetes management than their food-secure peers (Seligman et al., 2012). In a cluster-randomized controlled trial of 401 safety-net clinic patients with T2DM, 73\% were classified as food insecure (Heerman et al., 2016). In this sample, food insecurity was associated with higher $\mathrm{HbA1c}$, even after adjustment for age, gender, race, income, education, BMI, and duration of T2DM diagnosis (Heerman et al., 2016). Similar to Seligman et al.'s (2012) study, these food insecure patients were also less likely to adhere 
to various T2DM self-care behaviors (Heerman et al., 2016). In a multi-year cohort study of 391 patients of community clinics in Massachusetts, researchers found that, even after controlling for a number of demographics and heath information such as insulin use, Charlson comorbidity score, and food access, food insecurity was associated with $0.6 \%$ higher HbAlc than those who were food secure (Berkowitz et al., 2018). In another study of a safety-net population with T2DM, those who were food insecure had significantly higher HbAlcs than their food secure counterparts (Shalowitz et al., 2017).

It is worth noting that not all studies of safety-net resource clients found higher rates of T2DM. Though Ippolito et al.'s (2017) analysis of this population partially confirmed previously cited studies by finding that individuals in low/very-low food security households score significantly lower in various diabetes self-management behaviors, researchers found no significant difference between food security status' and HbA1c.

In sum, as observed from national and nearly all safety-net-specific studies, those experiencing a degree of food insecurity were more likely to have a diagnosis of T2DM; therefore, safety-net resources may be an opportune avenue for addressing T2DM though food security status.

\section{Measurable Risk Factors and Indicators}

Though there are numerous cofactors in the complex relationship between food insecurity and T2DM (Gucciardi, Vahabi, Norris, Del Monte, \& Farnum, 2014), two mediators have been herein chosen for discussion due to their nutritional relevance: diet quality and BMI. Before exploring these relationships in detail, Figure 1 provides a simplified overview of the proposed mechanism of a food pharmacy. 


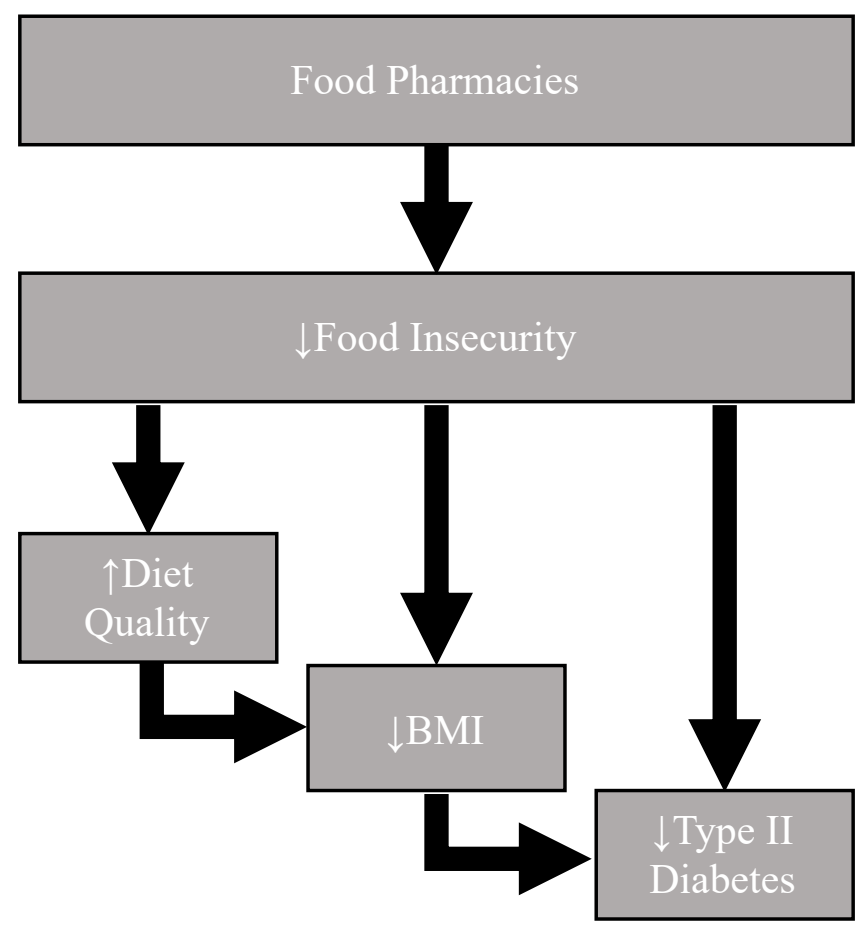

Figure 1. Hypothesized mechanism of the food pharmacy model.

Food insecurity and BMI. In a seemingly paradoxical relationship, food insecurity has repeatedly been associated with high BMI. As will be explored, this association appears to vary greatly between genders and possibly age groups; nevertheless, BMI remains valuable to consider due to its strength as a T2DM risk factor.

Upon analysis of data from a 2009 survey carried out by the US Centers for Disease Control (CDC), researchers found obesity $(\mathrm{BMI} \geq 30)$ to be significantly higher in food insecure adults overall, as well as in a wide range of subgroups including but not limited to women, non-Hispanic whites, non-Hispanic blacks, and non-Hispanic other races, and a range of household incomes: $<\$ 25,000, \$ 50,000$, and $\$ 74,900$ (Pan, Sherry, Njai, \& Blanck, 2012). Of note, this association was not significant in analysis of the male subgroup. In another older study of 9,541 subjects from the 1994-1996 data from the 
nationally representative Continuing Survey of Food Intakes by Individuals, food insecurity was significantly related to overweight status for women, but not men (Townsend, Peerson, Love, Achterberg, \& Murphy, 2001). More recently, in a longitudinal, retrospective, case-matched study of 457 participant and 1,974 controls found that, over an average of 3 years, those who were food insecure significantly increased in BMI when compared to control group (Chen Cheung et al., 2015). This relationship remained true when adjusted for age, sex, race/ethnicity, education level, insurance status, and spoken language (Chen Cheung et al., 2015).

A number of large studies indicate there are gender differences in the relationship between food insecurity and BMI. Data from 8,169 female participants of the 1998-1999 California Women's Health Survey showed that, as food insecurity status worsened, BMI rose in all races except Non-Hispanic Whites (Adams, Grummer-Strawn, \& Chavez, 2003). There are very few studies on a purely male population. Gooding, Walls, and Richmond (2012) examined longitudinal data for 6,604 young adult men and failed to find a correlation between food insecurity and BMI, as opposed to the 7,116 women in the study who exhibited a correlation between these factors. One analysis of 4,618 men did find a correlation between obesity and marginal food security (as compared to full food security), although these effects were smaller than in women of the same study and there was no correlation among men who were classified as food insecure, both with or without hunger (Wilde \& Peterman, 2006).

When this relationship is examined in children, studies also fail to produce a consensus. Alaimo, Olson, and Frongillo (2001) did not find a significant association 
between food insecurity status of 9,196 children aged 2-16 who participated in the National Health and Nutrition Examination Survey III (NHANES III). The only exception to this was non-Hispanic white, food insufficient girls ages 8-16, whom Alimino et al. (2001) found more likely to be overweight. One cross sectional study of 16,889 kindergarteners showed that food insecure children were $20 \%$ less likely to be overweight (Rose \& Bodor, 2006). Another 2001 study of 3,831 subjects from the Continuing Survey of Food Intakes by Individuals study of 1994-1996 found that there were no differences in weight between food-insecure and food-secure children (Casey, Szeto, Lensing, Bogle, \& Weber, 2001). Many studies about children utilize older datasets and there seems to be a lack of agreement on this topic.

Due to the apparent gender differences, BMIs usefulness as an indicator of food pharmacies' effect on food security status may be limited to female participants only. Regardless, it remains a relevant marker to track because of its robust association with T2DM.

BMI and T2DM. A number of varying T2DM screening recommendations have been published by different medical and government organizations, all of which include overweight and obesity as either the only risk factor, or the one of the first risk factors that indicate T2DM screening is appropriate (Pippitt, Li, \& Gurgle, 2016). Results from two large-scale studies were analyzed to determine if there was a relationship between BMI with risk of T2DM. The Study to Help Improve Early evaluation and management of risk factors Leading to Diabetes (SHIELD), conducted in 2004, and NHANES (19992002) yielded 127,420 and 4,257 participants, respectively (Bays, Chapman, \& Grandy, 
2007). Bays et al. (2007) found risk for T2DM rose very significantly as BMIs increased; the morbidly obese had the highest rates of T2DM in both datasets. Of those diagnosed with T2DM, $87 \%$ and $82 \%$ were classified overweight or obese in SHIELD and NHANES data, respectively (Bays et al., 2007). A case-controlled study of 12,179 cases and 25,177 controls found that patients who were overweight or obese have a 1.6 and 11.6, respectively, greater likelihood of being diagnosed with T2DM, as compared with patients with a normal BMI (Ganz et al., 2014). This is again confirmed in an older analysis of Nurses' Health Study (NHS) of 77,690 women and, separately, Health Professionals Follow-Up Study (HPFS) data of 46,060 men (Field et al., 2001). Within a 10 year period, both women and men in this cohort who were classified as overweight, but not obese, were three to four times more likely to develop T2DM than those who had a "normal" BMI (Field et al., 2001). Those with a BMI $\geq 35$ had around 20 times greater odds of developing T2DM (Field et al., 2001).

This association has become widely accepted, with the American Diabetes Association, the CDC, and the World Health Organization all listing excess weight as a risk factor for T2DM (“Diabetes,” 2019; "Prevention,” n.d.; "Who's at risk?,” 2019). Though much more could be said about potential mediators of this relationship, the importance of this connection lies in the changes that can be made through food pharmacies. If BMI is tracked as a reliable risk factor for T2DM, does weight loss indicate an improvement in T2DM status or risk? A 2015 systematic review and metaanalysis found that, among interventions promoting various lifestyle and dietary modifications for weight loss and cardio-metabolic health, 15/17 qualifying studies 
reported weight loss under 5\% at 12 months; only two studies reported greater than 5\% weight loss at one year (Franz, Boucher, Rutten-Ramos, \& VanWormer, 2015). In studies reporting $<5 \%$ weight loss, $\mathrm{HbA} 1 \mathrm{c}$ decreased an average of $0.2 \%$, an insignificant change from baseline, whereas participants of the two studies reporting $\geqq 5 \%$ weight loss had significant decreases in HbA1c, averaging 1.2\% (Franz et al., 2015). This suggests there is a threshold for weight loss at which significant decrease in HbAlc can be observed. This marker serves as an important indicator of T2DM risk, as well as a potential benchmark of program outcomes for food pharmacies.

Food insecurity and diet quality. One major challenge food pharmacies face is the reliance on food donations or community-sponsored funds to purchase food rations. This typically creates an inconsistent supply of healthy options due to a number of operational challenges faced by these institutions (Wetherill et al., 2019). If food pantries are unable to measurably and reliably provide boxes of a certain dietary quality to clients, food pantries may be simply considered to address food security status. This remains a valuable intervention, as research indicates that increased food security correlates with increased dietary quality.

Diet quality may be measured with a number of instruments. Two such surveys include The Healthy Eating Index (HEI), which was designed to measure adherence to government dietary recommendations, and the Alternative Healthy Eating Index (AHEI), which was designed to evaluate intake of foods associated with chronic diseases; both are common measures that have been validated as accurate representations of dietary adequacy and chronic disease risk (Chiuve et al., 2012; Guenther et al., 2014). Though 
many studies examine the specifics of diet composition among those experiencing food insecurity, for the sake of concision, only indicators of overall diet quality are discussed here. Using NHANES III (1988-1994) data, Bhattacharya, et al. (2004) found a significant correlation between lower family food security and lower HEI scores for children ages 12-17, and adults ages 18-65 years. More recently, Leung et al. (2014) used NHANES data from 1999-2008 to investigate this same relationship. Low food security was found to be indicative of lower HEI-2005 and AHEI-2010 scores (Leung et al., 2014). In 2015, the NHANES data from 2003 to 2010 again showed a significant negative relationship between any level of food insecurity and HEI-2010 scores (Nguyen, Shuval, Bertmann, \& Yaroch, 2015). Literature has yet to reach a consensus, as noted in a 2014 systematic review where only $26 \%$ of studies analyzed found inverse relationships between food insecurity and diet quality (Hanson \& Connor, 2014). Despite the need for additional studies, there is some evidence to suggest food insecurity effects diet quality scores.

Diet quality and T2DM. Decreases in diet quality scores may impact an individual's risk for T2DM. When scores are improved, even indirectly, there is potential for improvement in T2DM status. A longitudinal study by Fung, McCullough, Dam, and Hu (2007) observed over 80,000 women from the NHS over 18 years to determine if their AHEI scores correlated with a diagnosis of T2DM. The relative risk for a T2DM diagnosis between the top quintile AHEI scores and the bottom quintile was 0.64; however, those who improved their AHEI over 4 years had significantly reduced their risk of T2DM diagnosis, when compared to those who did not improve their low AHEI 
scores (Fung et al., 2007). This association is also true in men. In a cohort of 51,529 male health professionals which was followed for approximately 20 years, the top quintile of AHEI scores was associated with a T2DM diagnosis hazard ratio of 0.77 as compared to the bottom quintile (Koning et al., 2011). Koning et al. (2011) also found that, after multivariate adjustments were made, hazard ratios of T2DM diagnosis among HEI-2005 scores in the in the top and bottom quintiles scores did not differ significantly. Of importance, the author noted that their sample population was predominantly white and these results may not be applicable to diverse populations (Koning et al., 2011). In both Fung et al. (2007) and Koning et al.'s (2011) studies, higher intakes of fruits, vegetables, whole grains, nuts, legumes, and low saturated fat consumption was correlated with lower incidence of diabetes. A subsequent systematic review and meta-analysis, which included the two previously cited studies, found that, in a pooled relative risk analysis of qualifying studies, those who had the highest dietary quality scores (as measured by HEI, AHEI, and the Dietary Approaches to Stop Hypertension scale) had a relative risk of 0.78 as compared to the lowest diet quality scores (Schwingshackl \& Hoffmann, 2015).

Appropriateness of different diet quality indexes may vary depending on the race/ethnicity of the sample population. A large, multiethnic cohort study that included Hawaii residents who were either Japanese-American, white, Native Hawaiians, or other ancestries analyzed trends in diet quality scores and T2DM risk (Jacobs et al., 2015). Significant inverse associations were observed in both AHEI-2010 scores in men and women when all ethnicities were combined, but this association only held true in white participants in subgroup analysis; the continuous HEI-2010 score was only significantly 
associated with T2DM in white men and the categorized HEI-2010 wasn't associated in any group (Jacobs et al., 2015). Scores in another diet quality measure, the Dietary Approaches to Stop Hypertension (DASH) scale, were significantly inversely associated with T2DM risk in the sample as a whole, white males and females, Japanese-American women, and Native Hawaiian men (Jacobs et al., 2015).

Though these results do suggest that diet quality is related in varying degrees to T2DM risk, caution should be exercised when using the various metrics that measure diet quality, as substantial variation appears to exist between ethnicities. When selecting an instrument to measure quality, the ethnic/racial makeup of the population should be considered. Even with possible variations in some ethnic/racial groups, it appears there is reason to suggest increasing diet quality could impact T2DM status. As was discussed, studies have found food insecurity decreases diet quality; if food pharmacies address the food insecurity of their clients, diet quality may also be increased, possibly leading to decreased risk of T2DM.

Diet quality and BMI. Finally, diet quality has not only been associated with T2DM risk directly, but has also been related to BMI, which was previously described as a major risk factor of T2DM. In a large study of 15,658 NHANES III study participants, researchers found the odds of abdominal obesity to decrease significantly with each 10unit increase in HEI score in both women and men (Tande, Magel, \& Strand, 2010). Upon analysis of 2001-2006 NHANES data, researchers found a significant correlation between higher HEI-2005 scores and lower BMI in all age groups of men, but only 50-59 year-old women (Pate, Taverno Ross, Liese, \& Dowda, 2015). A review of observational 
studies on diet quality and BMI found also found inconsistent results (Togo, Osler, Sørensen, \& Heitmann, 2001). Togo et al. (2001) identified eleven out of the 30 qualified studies did not find a significant relationship between indicators of diet quality and BMI. Though there are few US-based studies in adolescents regarding this association, one long term analysis suggests there's a relationship between diet quality and BMI as young adults age into adulthood. In adolescents, one longitudinal study of 2,656 individuals carried out over 10 years found that a higher than average diet quality score at age 15 correlated to an average of $1.5 \mathrm{~kg}$ less weight gain over 10 years, and less increase in BMI over the same amount of time (Hu et al., 2016). The association between BMI and diet quality warrants further analysis, as there are a number of large-scale studies that suggest correlation, but several other studies suggest this relationship may not be clearcut.

To summarize, clients presenting at safety-net resources are likely to be experiencing some degree of food insecurity. Food insecurity is correlated with increased likelihood of T2DM diagnosis. This relationship is potentially mediated by BMI and diet quality, two factors that correlate with both food insecurity and T2DM. Addressing the clients' primary concern of food insecurity has potential to impact T2DM status, potentially by way of decreased BMI and/or increased diet quality.

\section{Safety-Net Resource Programs and T2DM-Related Outcomes}

Despite the growing popularity of this model, in situ food pharmacy studies have yet to include clinical changes in T2DM status as outcome measures. Three recent trials, however, have tested interventions similar to food pharmacies and may provide insight 
into how medically appropriate food provision may affect $\mathrm{HbAlc}$ and fasting blood glucose (FBG) in the safety-net population. Table 1 summarizes these studies.

It appears that, despite positive results in a preliminary observational trial, the two intervention studies found program efforts did not impact client's HbA1c or FBG to any significant extent (Palar et al., 2017; Seligman et al., 2015; Seligman, Smith, Rosenmoss, Marshall, \& Waxman, 2018). Both trials were relatively short; Palar (2017) noted their small sample size limited their analytical power. Seligman (2018) also cited the ethical responsibility to allow study participants access to standard food pantry offerings, outside of the intervention food provided for those with T2DM, as a potential confounding variable. Despite these limitations, both did report other positive changes in client health behaviors.

Due to the lack of research on T2DM indicators, further evaluation of food pharmacy programs may be drawn from studies of other diabetes related outcomes. Table 2 summarizes the results of selected studies. A number of variables were significantly improved, including self-efficacy, self-reported mental health, self-sufficiency (as it relates to responsibility and organization of health behaviors), and energy intake (Berkowitz et al., 2019; Martin, Colantonio, Picho, \& Boyle, 2016; Martin, Wu, Wolff, Colantonio, \& Grady, 2013; Wright et al., 2018). These outcomes only represent preliminary findings, as all have yet to be replicated in additional studies. Further, the literature has yet to form a consensus regarding outcomes that have been measured in more than one trial. Improvements in diet quality and fruit and vegetable intake were not seen in all food pantry studies: a number of authors found improvements, but others 
reported insignificant findings (Berkowitz et al., 2019; Martin et al., 2013; Wetherill, Chancellor McIntosh, Beachy, \& Shadid, 2018a; Wright et al., 2018). Fruit and vegetable intake has also been inconsistently impacted by food pharmacies, as one study found significant improvements, another reported intake changes were insignificant (Martin et al., 2013; Wetherill et al., 2018a). Interventions were also inconsistent in improving diet quality (Berkowitz et al., 2019; Wright et al., 2018). Together, these studies provide valuable insight into the possible impacts of food pharmacies and offer suggestions for organizational design to maximize impact yet cannot be relied upon to provide an answer to as the specific outcomes of these programs. 


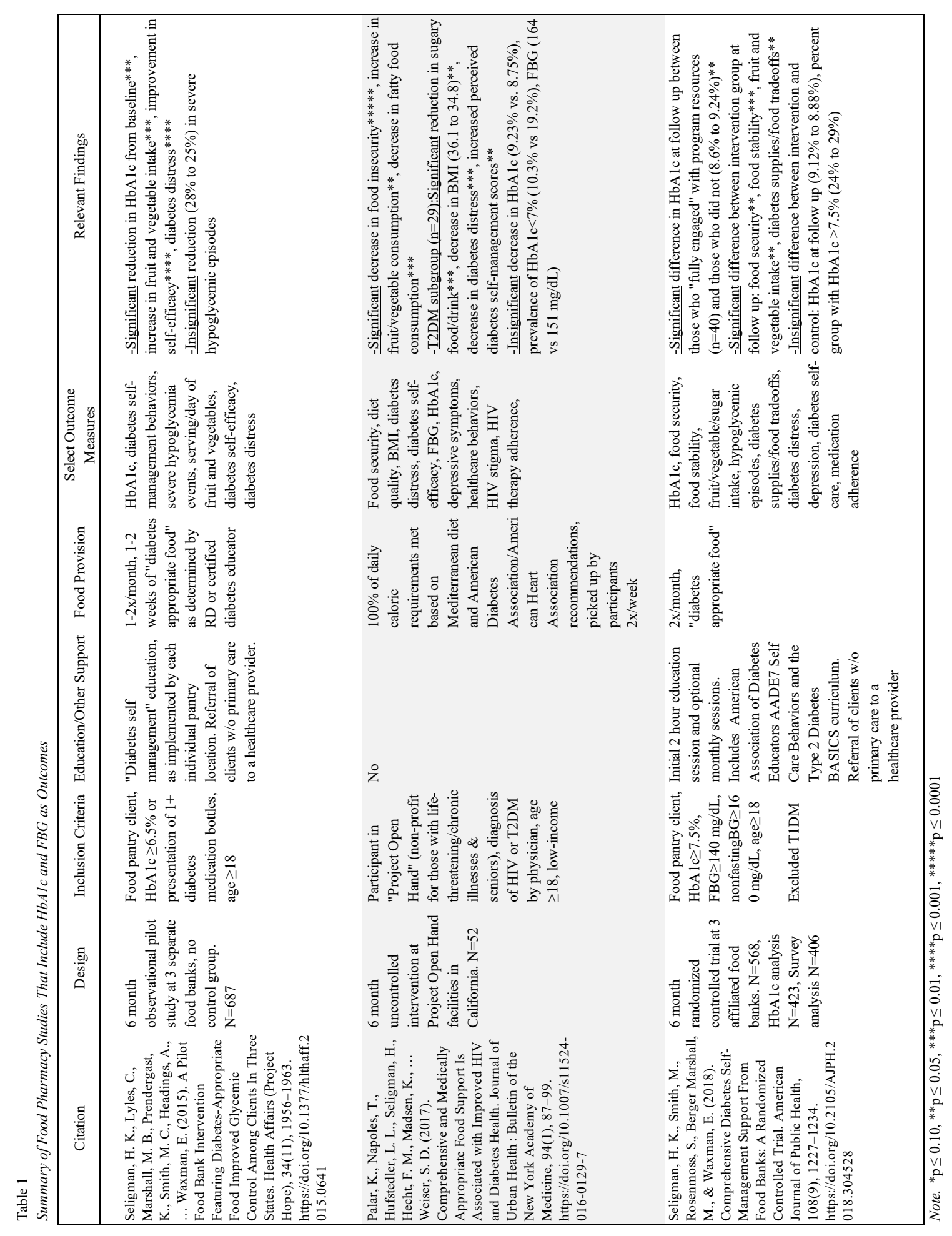




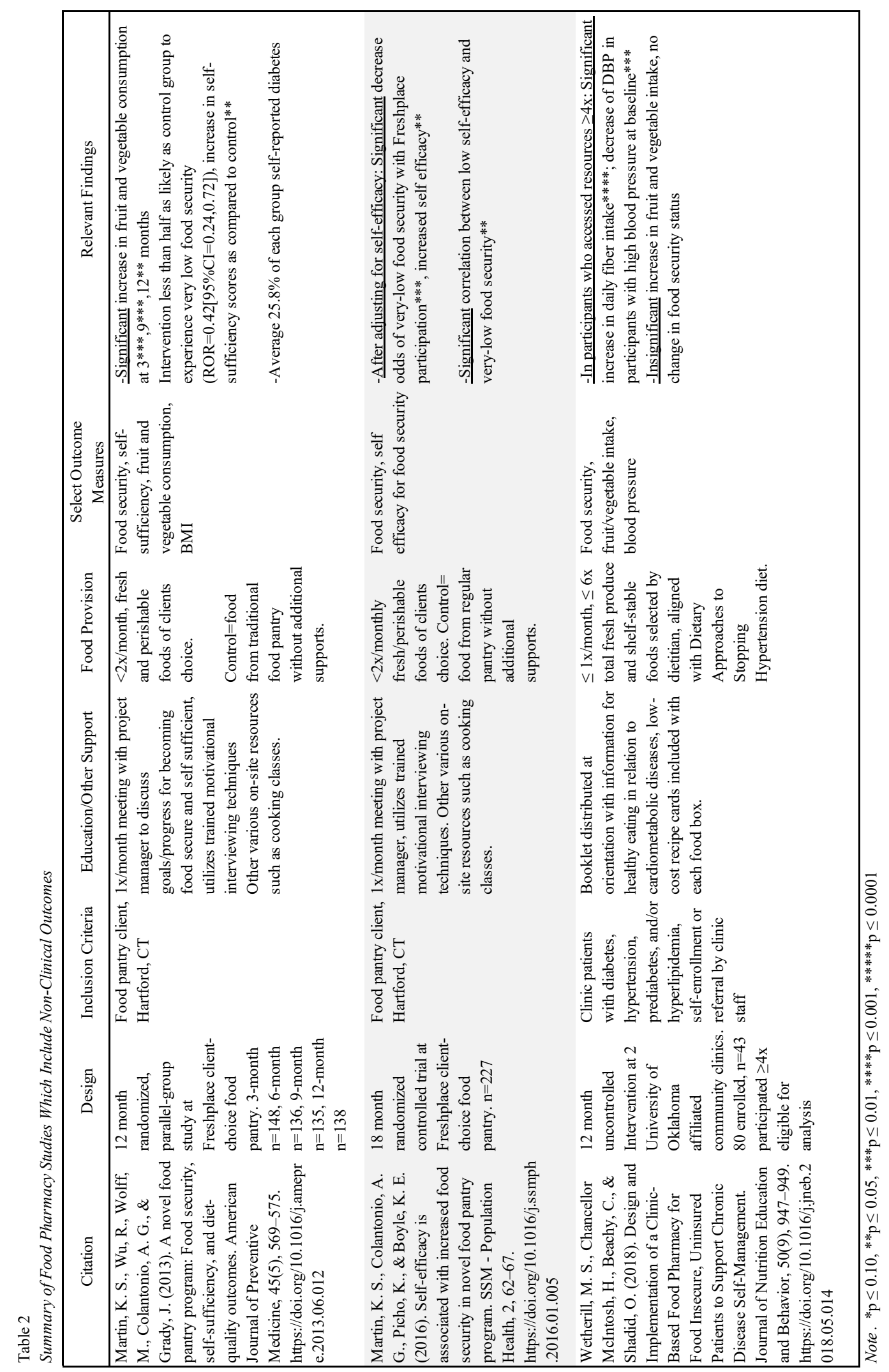




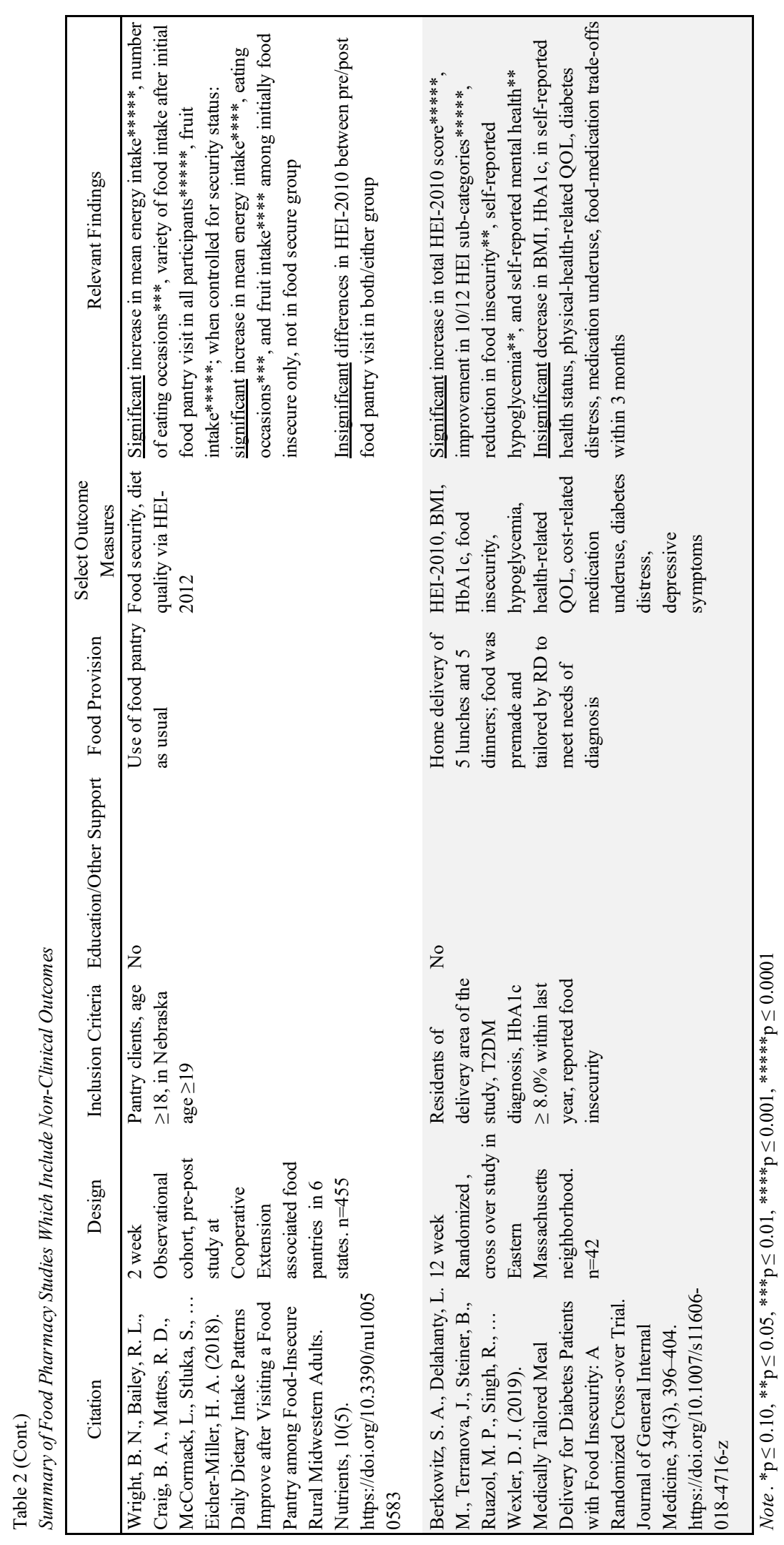




\section{Conclusion and Areas of Future Research}

Though the very few studies on food pharmacy design and T2DM markers have failed to consistently find significant improvements in $\mathrm{HbA} 1 \mathrm{c}$ and FBG, there is still promise in this treatment model due to the consistency of evidence suggesting food insecurity is correlated with increased T2DM rates and decreased disease care behaviors (Berkowitz, Gao, \& Tucker, 2014; Seligman, Laraia, \& Kushel, 2010; Walker et al., 2019). Food insecurity also correlates with elevated BMI in females and poorer diet quality (Berkowitz, Gao, \& Tucker, 2014; Seligman et al., 2010; Walker et al., 2019). Diet quality and BMI have been correlated with T2DM, serving as possible mediators in the food insecurity-T2DM relationship (Bays et al., 2007; Field et al., 2001; Fung et al., 2007; Ganz et al., 2014; Koning et al., 2011).

Food pharmacies have just recently emerged and continued study of actual food pharmacies is needed to identify possible shortcomings of this model. To date, there is no study of food pharmacies that evaluates T2DM outcomes in participants in situ. Studies of functioning programs may better illustrate real operational challenges that may be missed in intervention studies. 
CHAPTER 2. JOURNAL ARTICLE

ASSOCIATION OF FOOD PHARMACY PARTICIPATION WITH TYPE II DIABETES RISK FACTORS 


\begin{abstract}
Objective: To determine if participation in a food pharmacy program affects $\mathrm{HbA} 1 \mathrm{c}$, FBG, or BMI in those diagnosed with T2DM.

Design: Retrospective, observational study.

Setting: Food pharmacy run by a safety-net healthcare clinic, San Francisco Bay Area.

Participants: Clinic patients with T2DM (n=161).

Intervention(s): Once weekly opportunities to pick up boxes of "diabetes appropriate food."
\end{abstract}

Main Outcome Measure(s): HbA1c, FBG, and BMI.

Analysis: Spearman correlation analysis of participation rate and variable change, two sample t-tests comparing "high" and "low" participation groups, repeated measures analysis of variance (ANOVA) in subsample data; $\alpha=0.05$.

Results: Increased program participation correlated with reduction in BMI at 24 months $\left(\mathrm{r}_{\mathrm{s}}(29)=-0.39, \mathrm{p}=0.03\right)$, but not any other time. At 24 months, the "high" participation group $(\mathrm{M}=29.09, \mathrm{SD}=4.85)$ had a lower mean BMI compared to the "low" participation group $($ mean $=34.63, \mathrm{SD}=9.13, \mathrm{t}(21.32)=-2.07, \mathrm{p}=0.05)$. A repeated measures ANOVA found significant differences in HbA1c at 18 months, compared to baseline $(8.18 \pm 1.80 \mathrm{vs}$ 9.06 \pm 2.26 , respectively, $\mathrm{p}=0.04)$. However, HbA1c was not correlated with participation rate, nor was FBG.

Conclusions and Implications: This study found food pharmacy participation correlates with a reduction in BMI, but not $\mathrm{HbA} 1 \mathrm{c}$ or FBG. Food pharmacies with similar design 
may need to consider operational changes to better address T2DM in their clients. Further study is needed to fully understand this model.

Key Words: Food Insecurity, Type 2 Diabetes, HbA1c, Body Mass Index, Community Health 


\section{INTRODUCTION}

Food insecurity, defined as inconsistent access to enough food for a healthy, active lifestyle, affected over one in ten households in the US in $2018 .^{1}$ Though this represents a decline from 2011, when an estimated 15\% of the nation experienced food insecurity at some point, this condition continues to present a public health concern. ${ }^{1}$ Affected individuals often lack education, social support, or social capital. ${ }^{2-4}$ Women and minorities have been found to bear a disproportionate burden, especially when women are at the head of the household. ${ }^{2,3,5,6}$ Not only do these individuals face the stress of food insecurity, they are more likely to be diagnosed with a number of chronic conditions, including type 2 diabetes mellitus (T2DM), even after adjustment for covariates like body mass index (BMI) ${ }^{7-9}$ In studies of individuals with T2DM, those experiencing food insecurity are less likely to properly care for their diagnosis and have higher glycated hemoglobin (HbA1c), a clinical biomarker of this disease, than their food-secure peers, even when controlling for age, race, gender, and BMI. ${ }^{10-12}$

Of the various of mediators that have been suggested in the relationship between food insecurity and T2DM, two that have a particular relevance to nutrition are BMI and diet quality. Food insecurity has been consistently correlated with increased BMI in women, ${ }^{13-15}$ but not men ${ }^{16,17}$ or younger children. ${ }^{18-20}$ It is also associated with lower diet quality, as measured by the Healthy Eating Index or the Alternative Healthy Eating Index. ${ }^{21-23}$ Elevated BMI and poor diet quality are both correlated with increased rates of T2DM. Elevated BMI has been consistently shown to increase the risk of T2DM. ${ }^{24-26}$ Accordingly, major health organizations such as the American Diabetes Association, the 
Centers for Disease Control and Prevention (CDC), and the World Health Organization all list excess weight as a risk factor for T2DM. ${ }^{27-29}$ A number of epidemiological studies have shown that diet quality and T2DM are correlated, ${ }^{30,31}$ although some have questioned the validity of several common measures of diet quality in connection with this disease in multiethnic populations. ${ }^{31,32}$ Though more research should be conducted in minority populations, diet quality remains a variable of interest due to its inverse association with increased BMI. ${ }^{31,33,34}$ It is worth noting that some studies have found conflicting results between diet quality and $\mathrm{BMI}^{35,36}$ and more research should be done to clarify this relationship.

A number of resources are available to this population. Those faced with food insecurity are more likely to rely on safety-net resources, including food pantries and healthcare clinics providing medical care at free or reduced cost. ${ }^{1,37,38}$ In recognition of the disparate risks those experiencing food insecurity face, a number of safety-net resource agencies have pioneered "food pharmacies." Though no official definition exists and names for this model vary across locations, these programs seek to provide safety-net clients with specific diagnoses (namely, T2DM) with consistent access to medically appropriate food. To our knowledge, no in situ food pharmacy studies have reported on clinical markers of T2DM status. However, three intervention trials, which approximate food pharmacy design, have been performed. Despite thoughtful design, these studies did not consistently find measurable improvements in T2DM status. The first trial, an uncontrolled pilot intervention by Seligman et al., ${ }^{39}$ did find improvements in HbA1c after 6 months, but these same researchers' subsequent, more comprehensive randomized 
control trial found no significant changes within the same amount of time. Both of Seligman et al.'s ${ }^{39,40}$ interventions consisted of bi-weekly food provision, T2DM selfmanagement education, and personalized guidance by educators. ${ }^{40}$ These researchers noted that the randomized controlled trial was limited in duration and, even when attempts were made to lower barriers to participation, few clients fully engaged with resources available to them. ${ }^{40}$ Importantly, individuals who "fully engaged" with this trial's intervention did see significant decreases in HbAlc. ${ }^{40}$ In another uncontrolled trial, wherein participants with T2DM, recruited though a safety-net resource program, were provided "diabetes appropriate" food to account for $100 \%$ of daily caloric needs, no significant improvements in HbA1c or glycemic control were found..$^{41}$ Though these trials provide important preliminary insight into effects of this treatment model, studies of functioning food pharmacies are needed to identify strengths and shortcomings that may only be seen in real-world applications.

Food pharmacies have great potential to have a targeted impact on safety-net resource clients struggling with a T2DM diagnosis. A breadth of research suggests there are strong associations between food insecurity, a problem facing a majority of these clients, and T2DM. ${ }^{7-9,11,12}$ The present observational study aims to determine if food pharmacy participation correlates with decreases in $\mathrm{HbA1c}$, FBG, or BMI.

\section{METHODS}

\section{Subjects}

This was a retrospective, observational study of participants of a food pharmacy in the San Francisco Bay Area. Participants were included in this study if (1) they had been 
enrolled in the food pharmacy between January 2016 and May 2019, (2) had a baseline measurement of $\mathrm{HbA1c}, \mathrm{FBG}$, or BMI within \pm 11 days of enrollment, and (3) had at least one follow-up measurement of HbA1c, FBG, or BMI. Participants were qualified for each analysis of HbA1c, FBG, or BMI separately, and inclusion in one analysis did not indicate inclusion in all analyses. Data from 235 individuals were obtained and 161 individuals qualified for this study among HbA1c, FBG, and/or BMI analyses, combined. The only demographic information collected by researchers was age, as other demographics were not available. This study was classified as exempt by the San Jose State University Investigational Review Board (protocol S18152, see Appendix A) and approved by food pharmacy clinic executives.

\section{Food Pharmacy Program Design}

The food pharmacy program is run by a safety-net clinic with two locations that provides routine and specialized healthcare services to uninsured patients in the San Francisco Bay Area. Patients are referred to the food pharmacy by their primary care doctor at the clinic upon a diagnosis of T2DM. Upon referral, patients are able to pick up boxes of "diabetes appropriate" foods once a week at one of two food disbursal sites. One food disbursal site is located at the clinic and the other is off-site at a separate charity organization's facility. This separate charity is not affiliated with the food pharmacy in any other way. No specific dietary protocol is followed in planning contents of food boxes; clinic physicians and staff plan food boxes to contain items they determine to be appropriate for individuals with T2DM. The clinic relies on supplies from a partnering food bank to fill food boxes and box contents vary slightly depending on food 
availability. They generally include sources of complex carbohydrates, low sodium/sugar canned foods, fresh produce, and shelf-stable items like peanut butter and tuna. The amount of food received by each participant is determined by the number of individuals in a household. The amount of food disbursed weekly is intended to provide three to four days of food for the household. Patients periodically receive various, unstructured educational materials with their food boxes, such as recipe ideas.

\section{Data Collection and Analysis}

Data Collection. Food pharmacy participant data were collected by clinic staff on an ongoing basis. Upon enrollment, participants were assigned an ID number, which was different than their medical record number. All clinical lab results or attendance of food box pickup opportunities after enrollment were then electronically recorded in clinic databases and were catalogued by the food pharmacy participant ID number. Researchers obtained a dataset including all clinical results and food box pickup attendances recorded between January 2016 and May 2019. Independent variables were program participation rate and time since program enrollment, and dependent variables were $\mathrm{HbA} 1 \mathrm{c}, \mathrm{FBG}$, and BMI.

The number of clinical measurements participants had available for analysis varied greatly. To ensure equal weighting of participants one measurement was systematically selected for each participant at four time points $(6,12,18$, and 24 months) from data recorded within 0-6, 6-12, 12-18, and 18-24 months of enrollment. Though over three years of program data were available, the choice was made to limit analysis to these four time points in light of the average length of program enrollment (mean and 
$\mathrm{SD}=13.68 \pm 9.48$ months) and to account for participant attrition. At each time point, the most recent $\mathrm{HbAlc}$ and $\mathrm{BMI}$ measurement was selected from within the respective time interval. Due to the intrapersonal variability of $\mathrm{FBG},{ }^{42}$ the average of all measurements within \pm 8 weeks of each timepoint was used in analysis. It is important to note that participants rarely had measurements available at all time points; therefore, participants qualified for analysis in each time point independently. Inclusion at one time point did not necessitate inclusion at all time points. For example, an individual may be included in the analysis of 12,18, and 24 months but not qualify for inclusion at 6 months if measurements were not available within 0-6 months. For use in a repeated measures analysis, three additional subsamples were constructed with $\mathrm{HbA1c}$, FBG, and BMI data to include participants for whom measurements were available for 6,12 , and 18 months.

Lastly, program participation rate was defined as the proportion of food box pick-up opportunities cumulatively attended by each individual, up to the date of the final variable selected for analysis. For example, if a person has been enrolled in the food pharmacy for 10 weeks, but has only attended 2 food pickup opportunities, their participation rate is 0.20 . At every variable, participation rate reflected program attendance since the date of enrollment.

Data Analysis. Initial data organization and calculations were performed in Microsoft Excel, and statistical tests were performed using IBM SPSS Version 24 and 26 (IBM SPSS Statistics for Macintosh, Version 24.0, IBM Corp., Armonk, NY, 2016; IBM SPSS Statistics for Macintosh, Version 26.0, IBM Corp., Armonk, NY, 2019). Available demographic data were limited to age, as determined by date of birth. Each individual's 
proportion of change from baseline $(\propto \Delta)$ was calculated for $\mathrm{HbA} 1 \mathrm{c}, \mathrm{FBG}$, and BMI at 6 , 12,18 , and 24 months. Averages for $\propto \Delta$ within all independent variable and time points was obtained. All samples were determined to be abnormally, negatively distributed.

To determine if $\propto \Delta$ was correlated with participation rate, a Spearman correlation analysis was conducted for 6, 12, 18, and 24 months for BMI, HbA1c, and FBG. Spearman correlation analysis was chosen because data were not normally distributed and not all sample sizes were of sufficient size to justify parametric analysis ( $\mathrm{n}>30) .{ }^{43}$ In this same dataset, participants were split into "high" and "low" participation groups by determining the median participation rate at each time point. Those above the median were classified as "high," those below were classified "low." Two sample t-tests were then used to determine if mean $\propto \Delta$ or mean raw score differed between the two participation level groups.

To assess the relationship between participation rate and variable change in subsample data, a repeated measure analysis of variance (ANOVA) was conducted with BMI and HbA1c data. Due to the small sample size $(n=16)$, FBG was excluded, and sufficient sample sizes of BMI and HbA1c $(n>30)$ allowed for parametric analysis. ${ }^{43}$ Raw measurements of BMI and $\mathrm{HbAlc}$ were used to provide insight into actual change at these time points; BMI was reported as $\mathrm{kg} / \mathrm{m}^{2}$ and $\mathrm{HbAlc}$ was reported as a percentage of glycated hemoglobin. Means at baseline were compared with means at 6, 12, and 18 months. Further, two sample t-tests were conducted to compare means of the "high" and "low" participation groups within the subsample data, as described above. 
Lastly, to determine if participation rate decreased with increasing time since enrollment, a two-tailed Spearman correlation analysis was performed with HbA1c data at 12 months. In all analyses, $\alpha=0.05$.

\section{RESULTS}

Data from a total of 161 participants qualified for inclusion. Ages ranged from 30 to 78 years, with a mean and standard deviation (SD) of $57 \pm 8.9$ years. At the time of data requisition, the mean time since enrollment was 13.68 months. Table 3 depicts the raw measurements of the sample data at baseline.

\begin{tabular}{|c|c|c|c|c|c|}
\hline \multicolumn{2}{|c|}{ BMI $\left(\mathrm{kg} / \mathrm{m}^{2}\right)$} & \multicolumn{2}{|c|}{ HbA1c (\%) } & \multicolumn{2}{|c|}{$\mathrm{FBG}(\mathrm{mg} / \mathrm{dL})$} \\
\hline $\mathrm{n}$ & Mean(SD) & $\mathrm{n}$ & Mean(SD) & $\mathrm{n}$ & Mean(SD) \\
\hline 75 & $31.64(6.90)$ & 141 & $8.81(2.19)$ & 126 & $177.75(71.32)$ \\
\hline
\end{tabular}

Table 4 depicts the $\propto \Delta$ and participation rates as used in BMI, HbA1c, and FBG correlational analysis at each time point. As seen in Table 4, participation rates varied slightly between time points and variables. Figure 2 illustrates the negatively skewed distribution of participation rates in the HbAlc data at 12 months. Participants were found to have attended the pharmacy an average of 11 times a year. 


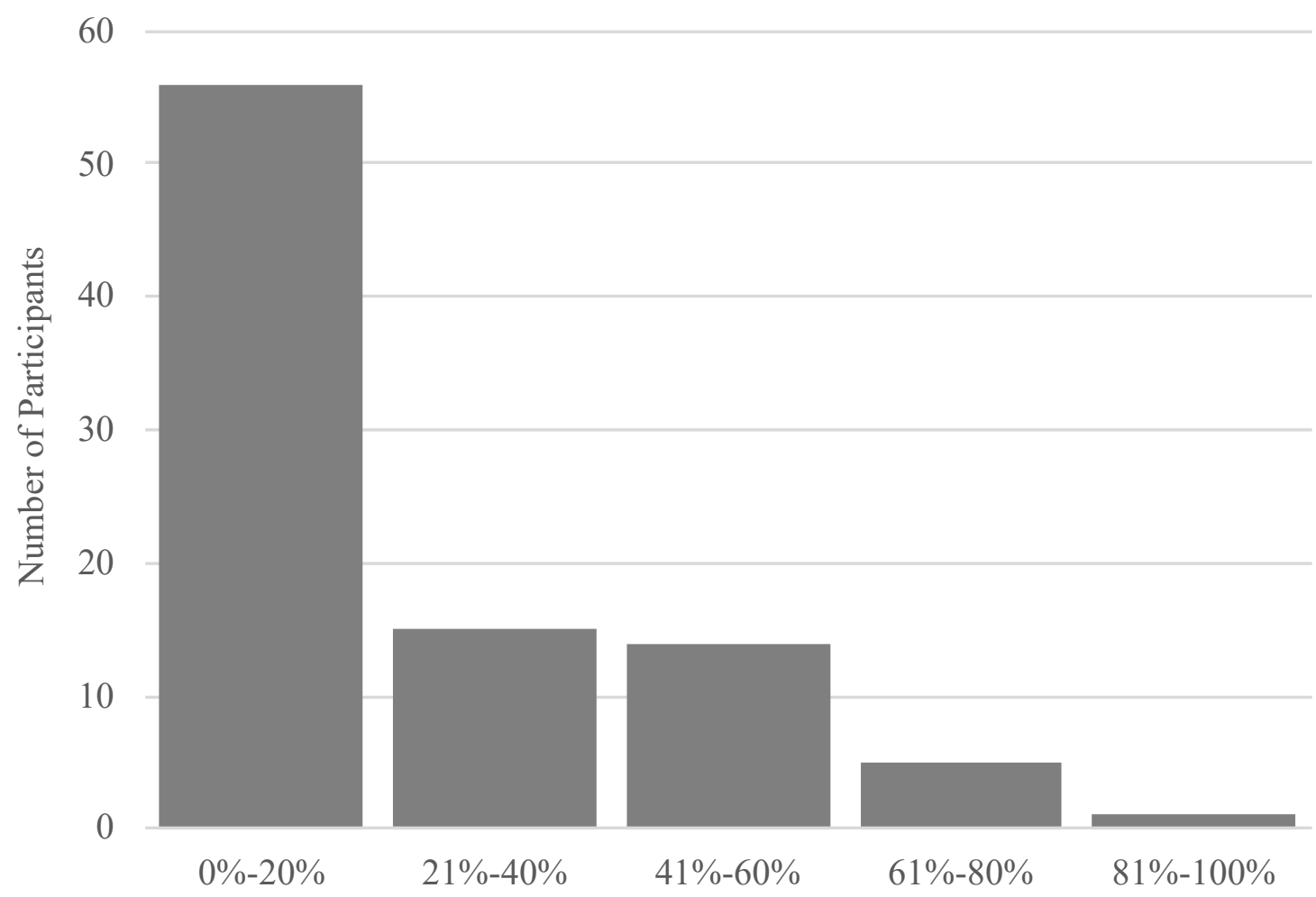

Total Percentage of Food Pickup Opportunities Attended at 12 Months

Figure 2. Frequency distribution of food pharmacy participation rates at 12 months in $\mathrm{HbA1c}$ data.

Table 4. Sample Characteristics of Proportion of Baseline and Rate of Participation in All Variables at All Time Points

\begin{tabular}{|c|c|c|c|c|c|c|c|c|c|}
\hline \multirow[b]{2}{*}{$\begin{array}{l}\text { Months Since } \\
\text { Enrollment }\end{array}$} & \multirow[b]{2}{*}{$\mathrm{n}$} & \multicolumn{2}{|c|}{ BMI } & \multicolumn{3}{|c|}{$\mathrm{HbA} 1 \mathrm{c}$} & \multicolumn{3}{|c|}{ FBG } \\
\hline & & $\operatorname{Median}^{\mathrm{a}}(\mathrm{IQR})$ & Median $^{\mathrm{b}}(\mathrm{IQR})$ & $\mathrm{n}$ & $\operatorname{Median}^{\mathrm{a}}(\mathrm{IQR})$ & $\operatorname{Median}^{\mathrm{b}}(\mathrm{IQR})$ & $\mathrm{n}$ & $\operatorname{Median}^{\mathrm{a}}(\mathrm{IQR})$ & Median $^{\mathrm{b}}(\mathrm{IQR})$ \\
\hline 6 & 69 & $1.00(0.03)$ & $0.16(0.27)$ & 119 & $0.95(0.21)$ & $0.19(0.33)$ & 70 & $0.94(0.40)$ & $0.17(0.29)$ \\
\hline 12 & 55 & $1.00(0.04)$ & $0.14(0.23)$ & 91 & $0.97(0.29)$ & $0.13(0.32)$ & 59 & $0.92(0.31)$ & $0.11(0.24)$ \\
\hline 18 & 48 & $0.99(0.06)$ & $0.09(0.18)$ & 68 & $0.98(0.37)$ & $0.11(0.23)$ & 37 & $1.03(0.54)$ & $0.11(0.24)$ \\
\hline 24 & 30 & $0.99(0.04)$ & $0.11(0.20)$ & 36 & $0.96(0.37)$ & $0.12(0.32)$ & 14 & $1.06(0.48)$ & $0.13(0.30)$ \\
\hline
\end{tabular}

BMI indicates Body mass index, HbA1c glycated hemoglobin, FBG fasting blood glucose, IQR interquartile range

${ }^{\mathrm{a}}$ Proportion of baseline at the time point

${ }^{\mathrm{b}}$ Rate of participation

As shown in Table 5, within the primary analysis group, participation rate was moderately, negatively correlated with $\propto \Delta$ of BMI after 24 months $\left(\mathrm{r}_{\mathrm{s}}(29)=-0.39\right.$, $\mathrm{p}=0.03$ ). Participation rate was also moderately, negatively correlated with FBG at 24 
months $\left(\mathrm{r}_{\mathrm{s}}(13)=-0.54, \mathrm{p}=0.05\right)$. Remaining variables and time points were not found to be significantly correlated. After seperating participants by participation level, a two sample t-test determined that those with "high" participation $(\mathrm{M}=29.09, \mathrm{SD}=4.85)$ had significantly lower BMIs at 24 months when compared to those with "low" participation (mean=34.63, $\mathrm{SD}=9.13, \mathrm{t}(21.32)=-2.073, \mathrm{p}=0.05)$. Complete two sample $\mathrm{t}$-test results are included in supplemental materials.

\section{Table 5. Correlation Between Food Pharmacy Participation Rate and Proportion of Baseline}

\begin{tabular}{|c|c|c|c|c|c|c|}
\hline \multirow[b]{2}{*}{$\begin{array}{c}\text { Months Since } \\
\text { Enrollment }\end{array}$} & & BMI & & $\mathrm{HbAlc}$ & & FBG \\
\hline & $\mathrm{n}$ & $\begin{array}{c}\text { Correlation } \\
\text { Coefficient }^{\mathrm{a}}(\mathrm{P} \text {-value })\end{array}$ & $\mathrm{n}$ & $\begin{array}{c}\text { Correlation } \\
\text { Coefficient }{ }^{\mathrm{a}}(\mathrm{P}-\mathrm{v} \text { alue })\end{array}$ & $\mathrm{n}$ & $\begin{array}{c}\text { Correlation } \\
\text { Coefficient }^{\mathrm{a}}(\mathrm{P} \text {-value })\end{array}$ \\
\hline 6 & 69 & $0.07(0.55)$ & 119 & $-0.04(0.68)$ & 70 & $0.11(0.35)$ \\
\hline 12 & 55 & $-0.14(0.31)$ & 91 & $-0.14(0.19)$ & 59 & $-0.10(0.43)$ \\
\hline 18 & 48 & $-0.21(0.15)$ & 68 & $-0.20(0.10)$ & 37 & $-0.07(0.69)$ \\
\hline 24 & 30 & $-0.39(0.03)^{*}$ & 36 & $-0.08(0.67)$ & 14 & $-0.54(0.05)^{* *}$ \\
\hline
\end{tabular}

BMI indicates Body mass index, HbA1c glycated hemoglobin, FBG fasting blood glucose $* \mathrm{p}=0.03, * * \mathrm{p}=0.05$

${ }^{\mathrm{a}}$ Spearman correlation analysis used to test the relationship between proportion of change in dependent variable from baseline and participation rate

Within the subsample of participants with measurements at baseline, 6,12 , and 18 months, a repeated measures ANOVA found a significant main effect of time on mean HbAlc $\left(\mathrm{F}(2.21,95.61)=4.44, \mathrm{p}=0.013, \eta_{\mathrm{p}}{ }^{2}=0.09\right)$. Post hoc testing using a Bonferroni correction found this variable was significantly lower at 18 months than at baseline ( $8.18 \pm 1.80$ vs $9.06 \pm 2.26$, respectively, $\mathrm{p}=0.04$ ) (Table 6). Time had no effect on BMI. 
Finally, Spearman correlation analysis found no significant correlation between time and participation rate in $\mathrm{HbA} 1 \mathrm{c}$ data at 12 months $(\mathrm{p}=0.36)$.

Table 6. Sample Characteristics of Repeated Measures Subsample

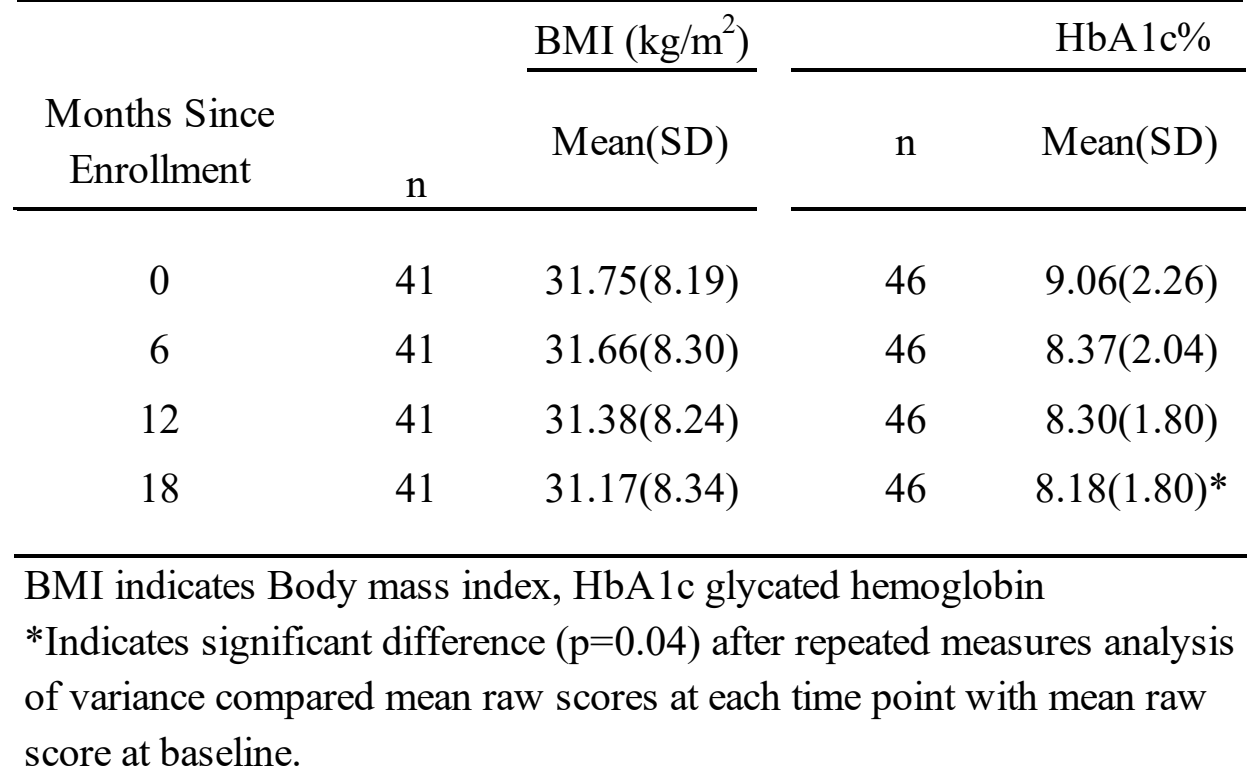

\section{DISCUSSION}

This study sought to determine if participation in a food-pantry program for safety-net clinic clients with diabetes would impact patients' HbA1c, FBG, or BMI. At 18 months of enrollment, mean $\mathrm{HbA} 1 \mathrm{c}$ was found to have been significantly decreased from baseline among participants who had measurements available at all three follow-up points. Despite this positive change, program participation was not correlated with HbA1c decreases in our other analyses, so this change cannot be linked to food pharmacy participation. Information about pharmacological treatments undertaken by the participants was not available, but it may be assumed that a number of participants are receiving medical treatment. The HbA1c change observed in this study is of similar magnitude of that frequently seen with use of popular T2DM drug treatments. ${ }^{44}$ At best, 
these results may only be taken as an indication that enrollment in a food pharmacy program does not inhibit other T2DM treatments initiated by the patient. Though participation did not correlate with decreases in $\mathrm{HbAlc}$, it did correlate with decreases in BMI at 24 months. At this time point, there was a 3\% reduction in average BMI, with those who had "high" participation rates having significantly lower measurements. It has been shown that a decrease in BMI of at least 5\% can lead to significant reductions in HbA1c. ${ }^{45}$ Though the observed BMI change in this study was not sufficient to impact HbAlc, it represents an area of promise for food pharmacies.

The present results indicate that there is a need to evaluate food pharmacies as they are currently designed. Researchers and program leaders should investigate methods of sustaining participation. Assessing barriers to attendance and modifying program design to facilitate higher, more sustained participation rates may lead to greater decreases in BMI and HbA1c than those observed in this study.

This study represents the first observational investigation of an active food pharmacy and the longest study period among controlled and observational trials alike. Even with these differences, this study confirms the findings of the two most similar investigations, wherein researchers also failed to detect a change in participant diabetes markers. ${ }^{40,41}$ Both authors note the short duration of each study, as the intervention was only 6 months long in each trial. Notably, both trials utilized an even more comprehensive intervention model than the present study, yet still struggled with engagement. Increasing participation may be important in the improvement of food pharmacy's effects. In Seligman et al.'s ${ }^{40}$ trial, the "most engaged" $20 \%$ of intervention participants showed a 
significant decrease in $\mathrm{HbAlc} .{ }^{40}$ Though there may not be any way to maintain full participation in a community program over the course of several years, qualitative feedback from past studies provides insight into attendee attitudes. Patients of a community clinic in the San Francisco Bay Area who were referred to food support services were systematically interviewed about their experience. Inaccessibility of resources due to location, timing, or wait times was the highest cited barrier to resource utilization. ${ }^{46}$ Other commonly stated reasons included failure to remember referral information, busy schedule, lack of ability to cook, perceived stability in access to food, and social stigma. ${ }^{46}$ Though there is reason to believe increased participation could increase food pantry's impact, results of Palar et al.' $\mathrm{s}^{41}$ study suggests high participation doesn't always yield decreased T2DM markers. In Palar et al.'s ${ }^{41}$ intervention, individuals with a history of the highest rates of participation in the program's services were selected for study and provided with $100 \%$ of dietary needs for 6 months, yet observed decreases in HbAlc and FBG did not reach significance. This draws into question the impact food provision can have on T2DM in this population, even when all calories are provided to participants. In future studies of food pharmacy programs, thoughtful design may produce results that quantify the effects of food provision and increased rates of participation on T2DM markers.

The major weakness of this study was the limited participant data available. Information on a number of potentially confounding variables, such as sex/gender, race/ethnicity, medication use, and other demographic variables, would have greatly enhanced interpretation of results. Specifically, because factors of interest such as BMI ${ }^{13-}$ 
${ }^{15}$ and food security ${ }^{2,3}$ appear to particularly affect women and minorities, consideration of sex/gender and race/ethnicity information would have allowed for a more nuanced analysis. Interpretation was also limited by the lack of a control group. In the context of a functioning food pharmacy, the use of randomized control groups is ethically limited; however, future studies may consider clinic patients who were not referred to the food pharmacy as one potential source of control data.

In closing, this study of an active food pharmacy in the San Francisco Bay Area found BMI to be significantly decreased with increased participation at 24 months of program enrollment. Additionally, those with a "high" level of participation had significantly lower BMIs than those with "low" participation. Program participation did not significantly impact HbA1c or FBG. Food pharmacies should re-evaluate their design if this program is to be considered effective at addressing T2DM. As this represents one of the first studies on functioning food pharmacies, more research is required to fully understand the extent of these programs' effects. Future studies should focus on including control groups and additional surveys to provide a more complete picture.

\section{IMPLICATIONS FOR RESEARCH AND PRACTICE}

Presently, the three previous trials and this observational study suggests that the food pharmacy model requires reassessment if statistically significant changes are to be seen in participant T2DM markers. The theoretical basis for this treatment method remains convincing. Established food pharmacies should consider barriers to participation and methods for increasing client retention. Structuring future studies to ensure consistent clinical measurements, large sample sizes, and the inclusion of pre/post surveys should 
strengthen findings and provide additional insight. Qualitative data and studies including groups with and without comprehensive diabetes self-management support would further enhance our understanding of ideal program designs. With persistence and continued study, the food pharmacy model may someday become a ubiquitous community resource. 


\section{REFERENCES}

1. Coleman-Jensen A, Rabbitt MP, Gregory CA, Singh A. Household food security in the United States in 2018. United States Department of Agriculture. http://www.ers.usda.gov/publications/pub-details/?pubid=94848. Published September 4, 2019. Accessed September 13, 2019.

2. Hernandez DC, Reesor LM, Murillo R. Food insecurity and adult overweight/obesity: gender and race/ethnic disparities. Appetite. 2017;117:373-378.

doi:10.1016/j.appet.2017.07.010

3. Pruitt SL, Leonard T, Xuan L, et al. Who is food insecure? Implications for targeted recruitment and outreach, national health and nutrition examination survey, 20052010. Prev Chronic Dis. 2016;13. doi:10.5888/pcd13.160103

4. Smith MD, Rabbitt MP, Coleman- Jensen A. Who are the world's food insecure? New evidence from the food and agriculture organization's food insecurity experience scale. World Development. 2017;93:402-412. doi:10.1016/j.worlddev.2017.01.006

5. Jung NM, Bairros FS de, Pattussi MP, Pauli S, Neutzling MB. Gender differences in the prevalence of household food insecurity: a systematic review and meta-analysis. Public Health Nutrition. 2017;20(5):902-916. doi:10.1017/S1368980016002925

6. Smith S, Malinak D, Chang J, et al. Implementation of a food insecurity screening and referral program in student-run free clinics in San Diego, California. Preventive Medicine Reports. 2017;5:134-139. doi:10.1016/j.pmedr.2016.12.007

7. Berkowitz SA, Gao X, Tucker KL. Food-insecure dietary patterns are associated with poor longitudinal glycemic control in diabetes: results from the Boston Puerto Rican health study. Diabetes Care. 2014;37(9):2587-2592. doi:10.2337/dc14-0753

8. Seligman HK, Laraia BA, Kushel MB. Food insecurity is associated with chronic disease among low-income NHANES participants. $J$ Nutr. 2010;140(2):304-310. doi: $10.3945 /$ jn. 109.112573

9. Walker RJ, Grusnick J, Garacci E, Mendez C, Egede LE. Trends in food insecurity in the USA for individuals with prediabetes, undiagnosed diabetes, and diagnosed diabetes. J GEN INTERN MED. 2019;34(1):33-35. doi:10.1007/s11606-018-4651-z

10. Berkowitz SA, Karter AJ, Corbie-Smith G, et al. Food insecurity, food "deserts," and glycemic control in patients with diabetes: a longitudinal analysis. Diabetes Care. 2018;41(6):1188-1195. doi:10.2337/dc17-1981 
11. Heerman W, Wallston KA, Osborn CY, et al. Research: Educational and psychological aspects Food insecurity is associated with diabetes self-care behaviours and glycaemic control. Diabet Med. 2016;33(6):844-850. doi:10.1111/dme.12896

12. Seligman HK, Jacobs EA, López A, Tschann J, Fernandez A. Food insecurity and glycemic control among low-income patients with type 2 diabetes. Diabetes Care. 2012;35(2):233-238. doi:10.2337/dc11-1627

13. Adams EJ, Grummer-Strawn L, Chavez G. Food insecurity is associated with increased risk of obesity in California women. J Nutr. 2003;133(4):1070-1074. doi:10.1093/jn/133.4.1070

14. Pan L, Sherry B, Njai R, Blanck HM. Food insecurity is associated with obesity among US adults in 12 states. Journal of the Academy of Nutrition and Dietetics. 2012;112(9):1403-1409. doi:10.1016/j.jand.2012.06.011

15. Townsend MS, Peerson J, Love B, Achterberg C, Murphy SP. Food insecurity is positively related to overweight in women. $J$ Nutr. 2001;131(6):1738-1745. doi:10.1093/jn/131.6.1738

16. Gooding HC, Walls CE, Richmond TK. Food insecurity and increased BMI in young adult women. Obesity. 2012;20(9):1896-1901. doi:10.1038/oby.2011.233

17. Wilde PE, Peterman JN. Individual weight change is associated with household food security status. $J$ Nutr. 2006;136(5):1395-1400. doi:10.1093/jn/136.5.1395

18. Alaimo K, Olson CM, Frongillo EA. Low family income and food insufficiency in relation to overweight in US children: is there a paradox? Arch Pediatr Adolesc Med. 2001;155(10):1161-1167. doi:10.1001/archpedi.155.10.1161

19. Casey PH, Szeto K, Lensing S, Bogle M, Weber J. Children in food-insufficient, low-income families: prevalence, health, and nutrition status. Arch Pediatr Adolesc Med. 2001;155(4):508-514. doi:10.1001/archpedi.155.4.508

20. Rose D, Bodor JN. Household food insecurity and overweight status in young school children: results from the Early Childhood Longitudinal Study. Pediatrics. 2006;117(2):464-473. doi:10.1542/peds.2005-0582

21. Bhattacharya J, Currie J, Haider S. Poverty, food insecurity, and nutritional outcomes in children and adults. $J$ Health Econ. 2004;23(4):839-862.

doi:10.1016/j.jhealeco.2003.12.008

22. Leung CW, Epel ES, Ritchie LD, Crawford PB, Laraia BA. Food insecurity is inversely associated with diet quality of lower-income adults. J Acad Nutr Diet. 2014;114(12):1943-1953.e2. doi:10.1016/j.jand.2014.06.353 
23. Nguyen BT, Shuval K, Bertmann F, Yaroch AL. The Supplemental Nutrition Assistance Program, food insecurity, dietary quality, and obesity among us adults. $\mathrm{Am}$ J Public Health. 2015;105(7):1453-1459. doi:10.2105/AJPH.2015.302580

24. Bays HE, Chapman RH, Grandy S. The relationship of body mass index to diabetes mellitus, hypertension and dyslipidaemia: comparison of data from two national surveys. Int J Clin Pract. 2007;61(5):737-747. doi:10.1111/j.17421241.2007.01336.x

25. Field AE, Coakley EH, Must A, et al. Impact of overweight on the risk of developing common chronic diseases during a 10-year period. Arch Intern Med. 2001;161(13):1581-1586. doi:10.1001/archinte.161.13.1581

26. Ganz ML, Wintfeld N, Li Q, Alas V, Langer J, Hammer M. The association of body mass index with the risk of type 2 diabetes: a case-control study nested in an electronic health records system in the United States. Diabetology \& Metabolic Syndrome. 2014;6(1):50. doi:10.1186/1758-5996-6-50

27. Diabetes. World Health Organization. https://www.who.int/news-room/factsheets/detail/diabetes. Published August 30, 2019. Accessed September 15, 2019.

28. Prevention. American Diabetes Association. https://www.diabetes.org/diabetesrisk/prevention. Accessed September 15, 2019.

29. Who's at risk? Center for Disease Control and Prevention. https://www.cdc.gov/diabetes/basics/risk-factors.html. Published August 28, 2019. Accessed September 15, 2019.

30. Fung TT, McCullough M, Dam RM van, Hu FB. A prospective study of overall diet quality and risk of type 2 diabetes in women. Diabetes Care. 2007;30(7):17531757. doi:10.2337/dc06-2581

31. Koning L de, Chiuve SE, Fung TT, Willett WC, Rimm EB, Hu FB. Diet-quality scores and the risk of type 2 diabetes in men. Diabetes Care. 2011;34(5):1150-1156. doi:10.2337/dc10-2352

32. Jacobs S, Harmon BE, Boushey CJ, et al. A priori-defined diet quality indexes and risk of type 2 diabetes: the Multiethnic Cohort. Diabetologia. 2015;58(1):98-112. doi:10.1007/s00125-014-3404-8

33. Hu T, Jacobs DR, Larson NI, Cutler GJ, Laska MN, Neumark-Sztainer D. Higher diet quality in adolescence and dietary improvements are related to less weight gain during the transition from adolescence to adulthood. J Pediatr. 2016;178:188-193.e3. doi:10.1016/j.jpeds.2016.08.026 
34. Tande DL, Magel R, Strand BN. Healthy Eating Index and abdominal obesity. Public Health Nutrition. 2010;13(2):208-214. doi:10.1017/S1368980009990723

35. Pate RR, Taverno Ross SE, Liese AD, Dowda M. Associations among physical activity, diet quality, and weight status in U.S. adults. Med Sci Sports Exerc. 2015;47(4):743-750. doi:10.1249/MSS.0000000000000456

36. Togo P, Osler M, Sørensen TI, Heitmann BL. Food intake patterns and body mass index in observational studies. Int J Obes Relat Metab Disord. 2001;25(12):17411751. doi:10.1038/sj.ijo.0801819

37. Bhattarai GR, Duffy PA, Raymond J. Use of food pantries and food stamps in low-income households in the United States. Journal of Consumer Affairs. 2005;39(2):276-298. doi:10.1111/j.1745-6606.2005.00015.x

38. Saviano E. California's safety-net clinics: a primer. https://www.chcf.org/publication/californias-safety-net-clinics-a-primer/. Published March 11, 2009. Accessed September 17, 2019.

39. Seligman HK, Lyles C, Marshall MB, et al. A pilot food bank intervention featuring diabetes-appropriate food improved glycemic control among clients in three states. Health Aff (Millwood). 2015;34(11):1956-1963. doi:10.1377/hlthaff.2015.0641

40. Seligman HK, Smith M, Rosenmoss S, Marshall MB, Waxman E. Comprehensive diabetes self-management support from food banks: a randomized controlled trial. $\mathrm{Am}$ J Public Health. 2018;108(9):1227-1234. doi:10.2105/AJPH.2018.304528

41. Palar K, Napoles T, Hufstedler LL, et al. Comprehensive and medically appropriate food support is associated with improved HIV and diabetes health. $J$ Urban Health. 2017;94(1):87-99. doi:10.1007/s11524-016-0129-7

42. Ollerton RL, Playle R, Ahmed K, Dunstan FD, Luzio SD, Owens DR. Day-to-day variability of fasting plasma glucose in newly diagnosed type 2 diabetic subjects. Diabetes Care. 1999;22(3):394-398. doi:10.2337/diacare.22.3.394

43. Uttley J. Power analysis, sample size, and assessment of statistical assumptionsimproving the evidential value of lighting research. LEUKOS. 2019;15(2-3):143-162. doi: $10.1080 / 15502724.2018 .1533851$

44. Upadhyay J, Polyzos SA, Perakakis N, et al. Pharmacotherapy of type 2 diabetes: an update. Metabolism. 2018;78:13-42. doi:10.1016/j.metabol.2017.08.010

45. Franz MJ, Boucher JL, Rutten-Ramos S, VanWormer JJ. Lifestyle weight-loss intervention outcomes in overweight and obese adults with type 2 diabetes: a systematic review and meta-analysis of randomized clinical trials. Journal of the 
Academy of Nutrition and Dietetics. 2015;115(9):1447-1463.

doi:10.1016/j.jand.2015.02.031

46. Marpadga S, Fernandez A, Leung J, Tang A, Seligman H, Murphy EJ. Challenges and successes with food resource referrals for food-insecure patients with diabetes. Perm J. 2019;23. doi:10.7812/TPP/18-097 


\section{SUPPLEMENTAL MATERIALS}

\begin{tabular}{|c|c|c|c|c|}
\hline $\begin{array}{l}\text { Months } \\
\text { Since } \\
\text { Enrollment }\end{array}$ & $\begin{array}{l}\text { Participation } \\
\text { Level }^{\mathrm{a}}\end{array}$ & $\mathrm{n}$ & $\begin{array}{c}\text { Raw Measurement } \\
{[\text { Mean(SD)] }}\end{array}$ & $\begin{array}{c}\text { Proportion of Change in } \\
\text { Measurement from } \\
\text { Baseline } \\
{[\text { Mean }(\mathrm{SD})]}\end{array}$ \\
\hline \multicolumn{5}{|c|}{ BMI } \\
\hline \multirow{2}{*}{6} & High & 34 & $31.30(7.56)$ & $1.00(0.05)$ \\
\hline & Low & 35 & $32.95(6.70)$ & $1.00(0.04)$ \\
\hline \multirow{2}{*}{12} & High & 26 & $30.43(8.46)$ & $0.97(0.09)$ \\
\hline & Low & 29 & $32.00(7.23)$ & $0.99(0.05)$ \\
\hline \multirow{2}{*}{18} & High & 24 & $31.39(6.30)$ & $0.98(0.08)$ \\
\hline & Low & 24 & $30.69(1.88)$ & $0.98(0.06)$ \\
\hline \multirow{2}{*}{24} & High & 15 & $29.09(4.85)^{*}$ & $0.97(0.04)$ \\
\hline & Low & 15 & $34.63(9.13)$ & $0.99(0.05)$ \\
\hline \multicolumn{5}{|c|}{$\mathrm{HbA} 1 \mathrm{c}$} \\
\hline \multirow{2}{*}{6} & High & 59 & $8.35(2.10)$ & $0.94(0.18)$ \\
\hline & Low & 60 & $8.09(1.92)$ & $0.93(0.20)$ \\
\hline \multirow{2}{*}{12} & High & 45 & $8.61(2.02)$ & $0.97(0.26)$ \\
\hline & Low & 46 & $8.10(1.85)$ & $0.98(0.27)$ \\
\hline \multirow{2}{*}{18} & High & 34 & $8.39(1.72)$ & $0.93(0.18)$ \\
\hline & Low & 34 & $8.08(1.88)$ & $0.95(0.23)$ \\
\hline \multirow{2}{*}{24} & High & 18 & $8.73(2.30)$ & $0.96(0.20)$ \\
\hline & Low & 18 & $8.47(2.15)$ & $0.99(0.32)$ \\
\hline \multicolumn{5}{|c|}{ FBG } \\
\hline \multirow{2}{*}{6} & High & 34 & $172.72(53.88)$ & $1.05(0.40)$ \\
\hline & Low & 34 & $170.87(57.45)$ & $0.94(0.42)$ \\
\hline \multirow{2}{*}{12} & High & 29 & $200.47(131.89)$ & $1.21(1.17)$ \\
\hline & Low & 29 & $151.81(53.23$ & $1.01(0.36)$ \\
\hline \multirow{2}{*}{18} & High & 18 & $188.94(87.81)$ & $0.81(0.19)$ \\
\hline & Low & 19 & $168.87(64.56)$ & $0.52(0.12)$ \\
\hline \multirow{2}{*}{24} & High & 7 & $141.00(55.99)$ & $0.96(0.27)$ \\
\hline & Low & 7 & $186.00(46.11)$ & $1.27(0.45)$ \\
\hline
\end{tabular}

BMI indicates Body mass index $\left(\mathrm{kg} / \mathrm{m}^{2}\right), \mathrm{HbA} 1 \mathrm{c}$ glycated hemoglobin (\%), FBG fasting blood glucose (mg/dL)

*High participation group significantly different than low participation group, $\mathrm{p}=0.05$

Two sample t-test used to compare means between groups.

${ }^{a}$ High participation: > median, low participation: $<$ median 


\begin{tabular}{|c|c|c|c|c|}
\hline $\begin{array}{l}\text { Months } \\
\text { Since } \\
\text { Enrollment }\end{array}$ & $\begin{array}{l}\text { Participation } \\
\text { Level }^{\mathrm{a}}\end{array}$ & $\mathrm{n}$ & $\begin{array}{c}\text { Raw Measurement } \\
{[\text { Mean(SD)] }}\end{array}$ & $\begin{array}{c}\text { Proportion of Change in } \\
\text { Measurement from } \\
\text { Baseline } \\
{[\text { Mean(SD)] }}\end{array}$ \\
\hline \multicolumn{5}{|c|}{$\overline{\text { BMI }}$} \\
\hline \multirow{2}{*}{6} & High & 34 & $32.21(5.23)$ & $0.99(0.03)$ \\
\hline & Low & 35 & $31.14(10.55)$ & $0.99(0.03)$ \\
\hline \multirow{2}{*}{12} & High & 26 & $30.95(5.08)$ & $0.99(0.05)$ \\
\hline & Low & 29 & $31.79(10.53)$ & $0.99(0.06)$ \\
\hline \multirow{2}{*}{18} & High & 24 & $30.01(4.61)$ & $0.98(0.04)$ \\
\hline & Low & 24 & $32.28(10.78)$ & $0.98(0.08)$ \\
\hline \multicolumn{5}{|c|}{$\mathrm{HbAlc}$} \\
\hline \multirow{2}{*}{6} & High & 59 & $8.20(1.85)$ & $0.89(0.16)$ \\
\hline & Low & 60 & $8.53(2.25)$ & $0.96(0.25)$ \\
\hline \multirow{2}{*}{12} & High & 45 & $8.29(1.71)$ & $0.90(0.24)$ \\
\hline & Low & 46 & $8.13(1.93)$ & $0.95(0.24)$ \\
\hline \multirow{2}{*}{18} & High & 34 & $8.07(1.51)$ & $0.88(0.16)$ \\
\hline & Low & 34 & $8.29(2.08)$ & $0.94(0.22)$ \\
\hline
\end{tabular}

BMI indicates Body mass index $\left(\mathrm{kg} / \mathrm{m}^{2}\right)$, HbAlc glycated hemoglobin (\%), FBG fasting blood glucose (mg/dL)

Two sample t-test used to compare means between groups, FBG not analyzed due to small sample size.

${ }^{\mathrm{a}}$ High participation: > median, low participation: $<$ median 


\section{CHAPTER 3. SUMMARY AND CONCLUSIONS}

\section{Summary}

In the US, safety-net resources represent a broad network of services targeted at underserved and at-risk populations. Food pantries and safety-net healthcare clinics represent a vital part of this network and play an irreplaceable role in addressing the food insecure population. Food insecurity, or inconsistent access to adequate and appropriate food puts an individual at risk for increased likelihood of numerous social and health conditions. One such condition is type 2 diabetes mellitus (T2DM). Though numerous mediators have been suggested in this relationship, two indicators of note are increased body mass index (BMI) and decreased diet quality, which both have been correlated with food insecurity. Food pantries and safety-net clinics have begun to address these increased risks by opening "food pharmacies." Though individual programs differ in what they call this model, they can be described as providing medically appropriate foods for a specific diagnosis in the safety-net setting.

Many food pantries have begun offering services to those with T2DM, but these programs have yet to be conclusively studied. Particularly lacking is research as to if food pharmacies yield significant change in T2DM markers. Only two published intervention studies and one pilot study have yet to describe changes in T2DM-specific biomarkers: glycated hemoglobin (HbAlc) and fasting blood glucose (FBG). Though the pilot study suggested this model could produce significant decreases in $\mathrm{HbAlc}$, a subsequent clinical trial of the same design failed to replicate these results. In a study with a similar, but 
slightly different design, comprehensive, medically tailored food provision did not produce significant decreases in $\mathrm{HbA} 1 \mathrm{c}$ or FBG.

The present study aimed to determine if participation in an established food pharmacy produced improvements in T2DM status or risk. After data from 161 individuals was analyzed, there was a significant correlation between increased program participation and decreased BMI after 24 months of participation. Conversely, mean HbAlc was significantly decreased from baseline in a repeated measures subgroup, but there was no correlation between program participation and changes in $\mathrm{HbA} 1 \mathrm{c}$ at any time point. In sum, although T2DM status was not improved, food pharmacy participants were found to have decreased their BMI, an important risk factor of T2DM.

\section{Conclusions}

As the first examination of T2DM clinical outcomes, this study serves as an important preliminary evaluation of functioning food pharmacies' effect; more research is required to fully understand the impact of these programs on diseases status. Future studies should consider including surveys and, although ethics limits the use of randomization in in situ applications of food pharmacies, control groups may serve to provide more meaningful results. Despite inconclusive initial evaluations, the food pharmacy model warrants continued research due to the strength of the underlying relationships between food insecurity and T2DM. 


\section{References}

Abdurahman, A. A., Chaka, E. E., Nedjat, S., Dorosty, A. R., \& Majdzadeh, R. (2019). The association of household food insecurity with the risk of type 2 diabetes mellitus in adults: a systematic review and meta-analysis. European Journal of Nutrition, 58(4), 1341-1350. doi: 10.1007/s00394-018-1705-2

Adams, E. J., Grummer-Strawn, L., \& Chavez, G. (2003). Food insecurity is associated with increased risk of obesity in California women. The Journal of Nutrition, 133(4), 1070-1074. doi: 10.1093/jn/133.4.1070

Alaimo, K., Olson, C. M., \& Frongillo, E. A. (2001). Low family income and food insufficiency in relation to overweight in US children: Is there a paradox? Archives of Pediatrics \& Adolescent Medicine, 155(10), 1161-1167. doi:

10.1001/archpedi.155.10.1161

Bays, H. E., Chapman, R. H., \& Grandy, S. (2007). The relationship of body mass index to diabetes mellitus, hypertension and dyslipidaemia: comparison of data from two national surveys. International Journal of Clinical Practice, 61(5), 737-747. doi: 10.1111/j.1742-1241.2007.01336.x

Bazerghi, C., McKay, F. H., \& Dunn, M. (2016). The role of food banks in addressing food insecurity: a systematic review. Journal of Community Health, 41(4), 732-740. doi: 10.1007/s10900-015-0147-5

Berkowitz, S. A., Baggett, T. P., Wexler, D. J., Huskey, K. W., \& Wee, C. C. (2013). Food insecurity and metabolic control among U.S. adults with diabetes. Diabetes Care, 36(10), 3093-3099. doi: 10.2337/dc13-0570

Berkowitz, S. A., Delahanty, L. M., Terranova, J., Steiner, B., Ruazol, M. P., Singh, R., ... Wexler, D. J. (2019). Medically tailored meal delivery for diabetes patients with food insecurity: a randomized cross-over trial. Journal of General Internal Medicine, 34(3), 396-404. doi: 10.1007/s11606-018-4716-z

Berkowitz, S. A., Gao, X., \& Tucker, K. L. (2014). Food-insecure dietary patterns are associated with poor longitudinal glycemic control in diabetes: results from the Boston Puerto Rican health study. Diabetes Care, 37(9), 2587-2592. doi:

$10.2337 / \mathrm{dc} 14-0753$

Berkowitz, S. A., Karter, A. J., Corbie-Smith, G., Seligman, H. K., Ackroyd, S. A., Barnard, L. S., ... Wexler, D. J. (2018). Food insecurity, food "deserts," and glycemic control in patients with diabetes: a longitudinal analysis. Diabetes Care, 41(6), 11881195. doi: $10.2337 / \mathrm{dc} 17-1981$ 
Bhattacharya, J., Currie, J., \& Haider, S. (2004). Poverty, food insecurity, and nutritional outcomes in children and adults. Journal of Health Economics, 23(4), 839-862. doi: 10.1016/j.jhealeco.2003.12.008

Casey, P. H., Szeto, K., Lensing, S., Bogle, M., \& Weber, J. (2001). Children in foodinsufficient, low-income families: prevalence, health, and nutrition status. Archives of Pediatrics \& Adolescent Medicine, 155(4), 508-514. doi: 10.1001/archpedi.155.4.508

Chen Cheung, H., Shen, A., Oo, S., Tilahun, H., Cohen, M. J., \& Berkowitz, S. A. (2015). Food insecurity and body mass index: a longitudinal mixed methods study, Chelsea, Massachusetts, 2009-2013. Preventing Chronic Disease, 12. doi: $10.5888 / \operatorname{pcd} 12.150001$

Chiuve, S. E., Fung, T. T., Rimm, E. B., Hu, F. B., McCullough, M. L., Wang, M., ... Willett, W. C. (2012). Alternative dietary indices both strongly predict risk of chronic disease. The Journal of Nutrition, 142(6), 1009-1018. doi: 10.3945/jn.111.157222

Coleman-Jensen, A., Rabbitt, M. P., Gregory, C. A., \& Singh, A. (2019, September 4). Household food security in the United States in 2018. Retrieved September 13, 2019, from United States Department of Agriculture website: http://www.ers.usda.gov/publications/pub-details/?pubid $=94848$

Diabetes. (2019, August 30). Retrieved from https://www.who.int/news-room/factsheets/detail/diabetes

Field, A. E., Coakley, E. H., Must, A., Spadano, J. L., Laird, N., Dietz, W. H., ... Colditz, G. A. (2001). Impact of overweight on the risk of developing common chronic diseases during a 10-year period. Archives of Internal Medicine, 161(13), 1581-1586. doi: 10.1001/archinte.161.13.1581

Franz, M. J., Boucher, J. L., Rutten-Ramos, S., \& VanWormer, J. J. (2015). Lifestyle weight-loss intervention outcomes in overweight and obese adults with type 2 diabetes: a systematic review and meta-analysis of randomized clinical trials. Journal of the Academy of Nutrition and Dietetics, 115(9), 1447-1463. doi: 10.1016/j.jand.2015.02.031

Fung, T. T., McCullough, M., Dam, R. M. van, \& Hu, F. B. (2007). A prospective study of overall diet quality and risk of type 2 diabetes in women. Diabetes Care, 30(7), 1753-1757. doi: 10.2337/dc06-2581

Ganz, M. L., Wintfeld, N., Li, Q., Alas, V., Langer, J., \& Hammer, M. (2014). The association of body mass index with the risk of type 2 diabetes: a case-control study 
nested in an electronic health records system in the United States. Diabetology \& Metabolic Syndrome, 6(1), 50. doi: 10.1186/1758-5996-6-50

Gooding, H. C., Walls, C. E., \& Richmond, T. K. (2012). Food insecurity and increased BMI in young adult women. Obesity, 20(9), 1896-1901. doi: 10.1038/oby.2011.233

Gucciardi, E., Vahabi, M., Norris, N., Del Monte, J. P., \& Farnum, C. (2014). The intersection between food insecurity and diabetes: a review. Current Nutrition Reports, 3(4), 324-332. doi: 10.1007/s13668-014-0104-4

Guenther, P. M., Kirkpatrick, S. I., Reedy, J., Krebs-Smith, S. M., Buckman, D. W., Dodd, K. W., ... Carroll, R. J. (2014). The Healthy Eating Index-2010 is a valid and reliable measure of diet quality according to the 2010 Dietary Guidelines for Americans. The Journal of Nutrition, 144(3), 399-407. doi: 10.3945/jn.113.183079

Gundersen, C. (2013). Food insecurity is an ongoing national concern. Advances in Nutrition, 4(1), 36-41. doi: 10.3945/an.112.003244

Hanson, K. L., \& Connor, L. M. (2014). Food insecurity and dietary quality in US adults and children: a systematic review. The American Journal of Clinical Nutrition, 100(2), 684-692. doi: 10.3945/ajcn.114.084525

Heerman, W. J., Wallston, K. A., Osborn, C. Y., Bian, A., Schlundt, D. G., Barto, S. D., \& Rothman, R. L. (2016). Food insecurity is associated with diabetes self-care behaviours and glycaemic control. Diabetic Medicine: A Journal of the British Diabetic Association, 33(6), 844-850. doi: 10.1111/dme.12896

Hernandez, D. C., Reesor, L. M., \& Murillo, R. (2017). Food insecurity and adult overweight/obesity: gender and race/ethnic disparities. Appetite, 117, 373-378. doi: 10.1016/j.appet.2017.07.010

Hu, T., Jacobs, D. R., Larson, N. I., Cutler, G. J., Laska, M. N., \& Neumark-Sztainer, D. (2016). Higher diet quality in adolescence and dietary improvements are related to less weight gain during the transition from adolescence to adulthood. The Journal of Pediatrics, 178, 188-193.e3. doi: 10.1016/j.jpeds.2016.08.026

Ippolito, M. M., Lyles, C. R., Prendergast, K., Marshall, M. B., Waxman, E., \& Seligman, H. K. (2017). Food insecurity and diabetes self-management among food pantry clients. Public Health Nutrition, 20(1), 183-189. doi: 10.1017/S1368980016001786

Jacobs, S., Harmon, B. E., Boushey, C. J., Morimoto, Y., Wilkens, L. R., Le Marchand, L., ... Maskarinec, G. (2015). A priori-defined diet quality indexes and risk of type 2 
diabetes: the multiethnic cohort. Diabetologia, 58(1), 98-112. doi: 10.1007/s00125014-3404-8

Jung, N. M., Bairros, F. S. de, Pattussi, M. P., Pauli, S., \& Neutzling, M. B. (2017). Gender differences in the prevalence of household food insecurity: a systematic review and meta-analysis. Public Health Nutrition, 20(5), 902-916. doi: $10.1017 / \mathrm{S} 1368980016002925$

Koning, L. de, Chiuve, S. E., Fung, T. T., Willett, W. C., Rimm, E. B., \& Hu, F. B. (2011). Diet-quality scores and the risk of type 2 diabetes in men. Diabetes Care, 34(5), 1150-1156. doi: $10.2337 / \mathrm{dc} 10-2352$

Leung, C. W., Epel, E. S., Ritchie, L. D., Crawford, P. B., \& Laraia, B. A. (2014). Food insecurity is inversely associated with diet quality of lower-income adults. Journal of the Academy of Nutrition and Dietetics, 114(12), 1943-1953.e2. doi: 10.1016/j.jand.2014.06.353

Marpadga, S., Fernandez, A., Leung, J., Tang, A., Seligman, H., \& Murphy, E. J. (2019). Challenges and successes with food resource referrals for food-insecure patients with diabetes. The Permanente Journal, 23. doi: 10.7812/TPP/18-097

Martin, K. S., Colantonio, A. G., Picho, K., \& Boyle, K. E. (2016). Self-efficacy is associated with increased food security in novel food pantry program. SSM Population Health, 2, 62-67. doi: 10.1016/j.ssmph.2016.01.005

Martin, K. S., Wu, R., Wolff, M., Colantonio, A. G., \& Grady, J. (2013). A novel food pantry program: food security, self-sufficiency, and diet-quality outcomes. American Journal of Preventive Medicine, 45(5), 569-575. doi: 10.1016/j.amepre.2013.06.012

Matheson, J., \& McIntyre, L. (2014). Women respondents report higher household food insecurity than do men in similar Canadian households. Public Health Nutrition, 17(1), 40-48. doi: 10.1017/S136898001300116X

Nguyen, B. T., Shuval, K., Bertmann, F., \& Yaroch, A. L. (2015). The Supplemental Nutrition Assistance Program, food insecurity, dietary quality, and obesity among us adults. American Journal of Public Health, 105(7), 1453-1459. doi: 10.2105/AJPH.2015.302580

Ogurtsova, K., da Rocha Fernandes, J. D., Huang, Y., Linnenkamp, U., Guariguata, L., Cho, N. H., ... Makaroff, L. E. (2017). IDF Diabetes Atlas: global estimates for the prevalence of diabetes for 2015 and 2040. Diabetes Research and Clinical Practice, 128, 40-50. doi: 10.1016/j.diabres.2017.03.024 
Palar, K., Napoles, T., Hufstedler, L. L., Seligman, H., Hecht, F. M., Madsen, K., ... Weiser, S. D. (2017). Comprehensive and medically appropriate food support is associated with improved HIV and diabetes health. Journal of Urban Health : Bulletin of the New York Academy of Medicine, 94(1), 87-99. doi: 10.1007/s11524016-0129-7

Pan, L., Sherry, B., Njai, R., \& Blanck, H. M. (2012). Food insecurity is associated with obesity among US adults in 12 states. Journal of the Academy of Nutrition and Dietetics, 112(9), 1403-1409. doi: 10.1016/j.jand.2012.06.011

Pate, R. R., Taverno Ross, S. E., Liese, A. D., \& Dowda, M. (2015). Associations among physical activity, diet quality, and weight status in U.S. adults. Medicine and Science in Sports and Exercise, 47(4), 743-750. doi: 10.1249/MSS.0000000000000456

Pippitt, K., Li, M., \& Gurgle, H. E. (2016). Diabetes mellitus: screening and diagnosis. American Family Physician, 93(2), 103-109. Retrieved from https://www.aafp.org/afp/2016/0115/p103.html

Prevention. (n.d.). Retrieved September 15, 2019 from https://www.diabetes.org/diabetes-risk/prevention

Pruitt, S. L., Leonard, T., Xuan, L., Amory, R., Higashi, R. T., Nguyen, O. K., ... Swales, S. (2016). Who is food insecure? Implications for targeted recruitment and outreach, national health and nutrition examination survey, 2005-2010. Preventing Chronic Disease, 13. doi: 10.5888/pcd13.160103

Radimer, K. L., \& Radimer, K. L. (2002). Measurement of household food security in the USA and other industrialised countries. Public Health Nutrition, 5(6A), 859-864. doi: 10.1079/PHN2002385

Raghupathi, W., \& Raghupathi, V. (2018). An empirical study of chronic diseases in the United States: a visual analytics approach to public health. International Journal of Environmental Research and Public Health, 15(3). doi: 10.3390/ijerph15030431

Robaina, K. A., \& Martin, K. S. (2013). Food insecurity, poor diet quality, and obesity among food pantry participants in Hartford, CT. Journal of Nutrition Education and Behavior, 45(2), 159-164. doi: 10.1016/j.jneb.2012.07.001

Rose, D., \& Bodor, J. N. (2006). Household food insecurity and overweight status in young school children: results from the Early Childhood Longitudinal Study. Pediatrics, 117(2), 464-473. doi: 10.1542/peds.2005-0582 
Saviano, E. (2009, March 11). California's safety-net clinics: a primer. Retrieved from https://www.chcf.org/publication/californias-safety-net-clinics-a-primer/

Schwingshackl, L., \& Hoffmann, G. (2015). Diet quality as assessed by the Healthy Eating Index, the Alternate Healthy Eating Index, the Dietary Approaches to Stop Hypertension Score, and health outcomes: a systematic review and meta-analysis of cohort studies. Journal of the Academy of Nutrition and Dietetics, 115(5), 780800.e5. doi: 10.1016/j.jand.2014.12.009

Seligman, H. K., Jacobs, E. A., López, A., Tschann, J., \& Fernandez, A. (2012). Food insecurity and glycemic control among low-income patients with type 2 diabetes. Diabetes Care, 35(2), 233-238. doi: 10.2337/dc11-1627

Seligman, H. K., Laraia, B. A., \& Kushel, M. B. (2010). Food insecurity is associated with chronic disease among low-income NHANES participants. The Journal of Nutrition, 140(2), 304-310. doi: 10.3945/jn.109.112573

Seligman, H. K., Lyles, C., Marshall, M. B., Prendergast, K., Smith, M. C., Headings, A., ... Waxman, E. (2015). A pilot food bank intervention featuring diabetes-appropriate food improved glycemic control among clients in three states. Health Affairs (Project Hope), 34(11), 1956-1963. doi: 10.1377/hlthaff.2015.0641

Seligman, H. K., Smith, M., Rosenmoss, S., Berger Marshall, M., \& Waxman, E. (2018). Comprehensive diabetes self-management support from food banks: a randomized controlled trial. American Journal of Public Health, 108(9), 1227-1234. doi: 10.2105/AJPH.2018.304528

Shalowitz, M. U., Eng, J. S., McKinney, C. O., Krohn, J., Lapin, B., Wang, C.-H., \& Nodine, E. (2017). Food security is related to adult type 2 diabetes control over time in a United States safety net primary care clinic population. Nutrition \& Diabetes, 7(5), e277. doi: 10.1038/nutd.2017.18

Smith, M. D., Rabbitt, M. P., \& Coleman- Jensen, A. (2017). Who are the world's food insecure? New evidence from the food and agriculture organization's food insecurity experience scale. World Development, 93, 402-412. doi:

10.1016/j.worlddev.2017.01.006

Smith, S., Malinak, D., Chang, J., Perez, M., Perez, S., Settlecowski, E., ... Aedo, S. (2017). Implementation of a food insecurity screening and referral program in student-run free clinics in San Diego, California. Preventive Medicine Reports, 5, 134-139. doi: 10.1016/j.pmedr.2016.12.007 
Tande, D. L., Magel, R., \& Strand, B. N. (2010). Healthy Eating Index and abdominal obesity. Public Health Nutrition, 13(2), 208-214. doi: 10.1017/S1368980009990723

Togo, P., Osler, M., Sørensen, T. I., \& Heitmann, B. L. (2001). Food intake patterns and body mass index in observational studies. International Journal of Obesity and Related Metabolic Disorders: Journal of the International Association for the Study of Obesity, 25(12), 1741-1751. doi: 10.1038/sj.ijo.0801819

Townsend, M. S., Peerson, J., Love, B., Achterberg, C., \& Murphy, S. P. (2001). Food insecurity is positively related to overweight in women. The Journal of Nutrition, 131(6), 1738-1745. doi: 10.1093/jn/131.6.1738

USDA ERS-Survey Tools. (2019, September 4). Retrieved September 30, 2019 from https://www.ers.usda.gov/topics/food-nutrition-assistance/food-security-in-theus/survey-tools/

Walker, R. J., Grusnick, J., Garacci, E., Mendez, C., \& Egede, L. E. (2019). Trends in food insecurity in the USA for individuals with prediabetes, undiagnosed diabetes, and diagnosed diabetes. Journal of General Internal Medicine, 34(1), 33-35. doi: $10.1007 / \mathrm{s} 11606-018-4651-\mathrm{z}$

Wetherill, M. S., Chancellor McIntosh, H., Beachy, C., \& Shadid, O. (2018b). Design and implementation of a clinic-based food pharmacy for food insecure, uninsured patients to support chronic disease self-management. Journal of Nutrition Education and Behavior, 50(9), 947-949. doi: 10.1016/j.jneb.2018.05.014

Wetherill, M. S., Williams, M. B., White, K. C., \& Seligman, H. K. (2019). Characteristics of households of people with diabetes accessing US food pantries: Implications for diabetes self-management education and support. The Diabetes Educator, 45(4), 397-407. doi: 10.1177/0145721719857547

Who's at Risk? (2019, August 28). Retrieved September 15, 2019, from https://www.cdc.gov/diabetes/basics/risk-factors.html

Wilde, P. E., \& Peterman, J. N. (2006). Individual weight change is associated with household food security status. The Journal of Nutrition, 136(5), 1395-1400. doi: $10.1093 / \mathrm{jn} / 136.5 .1395$

Wright, B. N., Bailey, R. L., Craig, B. A., Mattes, R. D., McCormack, L., Stluka, S., ... Eicher-Miller, H. A. (2018). Daily dietary intake patterns improve after visiting a food pantry among food-insecure rural Midwestern adults. Nutrients, 10(5). doi: $10.3390 /$ nu 10050583 
Xu, G., Liu, B., Sun, Y., Du, Y., Snetselaar, L. G., Hu, F. B., \& Bao, W. (2018). Prevalence of diagnosed type 1 and type 2 diabetes among US adults in 2016 and 2017: population based study. $B M J, 362$, k1497. doi: 10.1136/bmj.k1497 


\section{APPENDIX A}

\section{\begin{tabular}{l|l|l|l} 
SAN JOSE STATE & $\begin{array}{l}\text { Office of Research } \\
\text { Division of } \\
\text { Academic Affairs }\end{array}$ & $\begin{array}{l}\text { San José State University } \\
\text { One Washington Square } \\
\text { San José, CA 95192-0025 }\end{array}$ & $\begin{array}{l}\text { TEL: 408-924-2272 } \\
\text { officeofresearch@sjsu.edu } \\
\text { sjsu.edu/research }\end{array}$
\end{tabular}}

SAN JOSE STATE UNIVERSITY

HUMAN SUBJECTS INSTITUTIONAL REVIEW BOARD

IRB Notice of Approval

Date of Approval: 3/11/2019

Study Title: Evaluation of a Diabetes Intervention Program at a Safety Net Clinic

Primary Investigator(s): Dr. John Gieng

Student(s): Breanne Vinogradoff

Other Team Members: Dr. Giselle Pignotti (co-PI)

Funding Source: None

IRB Protocol Tracking Number: S18152

Type of Review

\ Exempt Registration: Category of approval §46.104(d)(4iii)

$\square$ Expedited Review: Category of approval $\$ 46.110(\mathrm{a})($ )

$\square$ Full Review

$\square$ Modifications

$\square$ Continuing Review

Special Conditions

$\square$ Waiver of signed consent approved

Waiver of some or all elements of informed consent approved: no consent required

$\square$ Risk determination for device:

$\square$ Other:

Continuing Review

$\bigotimes$ Is not required. Principal Investigator must file a status report with the Office of Research one year from the approval date on this notice to communicate whether the research activity is ongoing. Failure to file a status report will result in closure of the protocol and destruction of the protocol file after three years.

$\square$ Is required. An annual continuing review renewal application must be submitted to the Office 